\title{
Forced Response Testing of an Axi-Centrifugal Turboshaft Engine
}

\author{
A. Karl Owen \\ Vehicle Propulsion Directorate \\ U.S. Army Research Laboratory \\ Lewis Research Center \\ Cleveland, Ohio \\ Duane L. Mattern \\ NYMA, Inc. \\ Brook Park, Ohio \\ Dzu K. Le and Donald C. Braun \\ Lewis Research Center \\ Cleveland, Ohio
}

Prepared for the

32nd Joint Propulsion Conference

cosponsored by AIAA, ASME, SAE, and ASEE

Lake Buena Vista, Florida, July 1-3, 1996
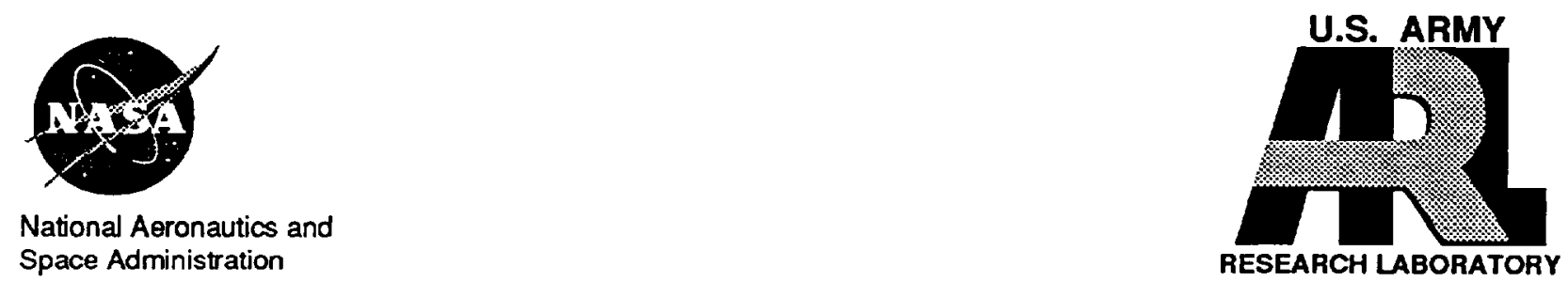


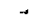




\section{FORCED RESPONSE TESTING OF AN AXI-CENTRIFUGAL TURBOSHAFT ENGINE}

by

\author{
A. Karl Owen \\ U.S. Army Vehicle Propulsion Directorate \\ NASA Lewis Research Center \\ Cleveland, Oh, USA
}

Dzu K. Le

Control Systems Branch

NASA Lewis Research Center

Cleveland, Oh, USA

1. Now with Scientific Monitoring Inc., Tempe, Az, USA

\section{NOMENCLATURE}

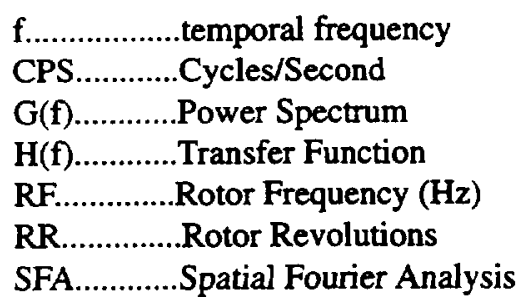

Dynamic data from tests of a T55-L-712 engine are presented. Engine stall/surge data were analyzed using digital signal processing techniques. In addition, forced response testing (system identification studies) was done at various engine speeds. Forced response testing was done using eight jet ejectors approximately equally circumferentially spaced about the compressor front face. This paper presents some preliminary results for the ground idle (approximately $60 \%$ of design speed) point. Brief descriptions of the jet injection system, the test matrix, and analysis techniques used are presented. Results of these analyses indicate a substantial transfer of energy across the compressor first stage at some frequencies and that the ejectors are effective in modifying the local flow conditions in front of the first compressor stage.

SFA...........Spatial Fourier Analysis

\author{
Duane L. Mattem ${ }^{1}$ \\ NYMA, Inc. \\ NASA Lewis Research Center \\ Cleveland, Oh, USA
}

Donald C. Braun

Scientific Data Systems and Applications Branch

NASA Lewis Research Center

Cleveland, Oh, USA

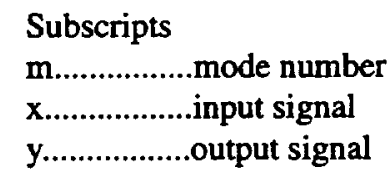

Superscript

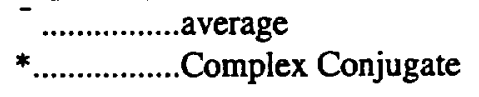

\section{INTRODUCTION}

Compressors in gas turbine engines are subject to aerodynamic instabilities known as rotating stall and surge if required to operate at or beyond certain massflow/pressure rise/rotor speed points. On the compressor map, these points form a line known as the stall/surge line. When rotating stall or surge occurs, gas turbine engine performance is seriously degraded or not possible. To prevent operation in these regions, the gas turbine cycle is normally designed to require compressor operation away from the surge line on an "op line". This provides an appropriate margin to assure continued engine operation in the event of unplanned system operation excursions due to, for example, inlet distortion. However, this normally results in accepting less than

This paper is a declared work of the United States government and is not subject to copyright protection in the United States 
optimal engine performance. The ability to actively suppress these aerodynamic instabilities would allow operation nearer this surge line, thereby improving gas turbine efficiencies.

Potential improvements in gas turbine engine efficiencies due to active compressor stability enhancement (active stall control) suggest that the development of this technology should be encouraged. Indeed, studies at AlliedSignal (Stratford) indicated a $4.0 \%$ reduction in design point specific fuel consumption for the T55 engine $^{1}$ with studies of advanced designs indicating potentially greater improvements. This promised performance improvement has promoted considerable interest in this technology area.

To further the development of this technology, the US Army Vehicle Propulsion Directorate and the NASA Lewis Research Center (LeRC) initiated an effort to demonstrate an "active stability control" device that would increase compression system stability across a broad range of operating speeds in an axi-centrifugal turboshaft engine. The program began with initial rig testing of surge events in an AlliedSignal T55-L-712 compressor rig (completed June of 1993). Preliminary analysis of data ${ }^{4}$ indicated that precursor waves could be identified in the compression system.

A T55-L-712 turboshaft engine was instrumented and installed at LeRC. Surge testing began March 1995. A proportional high speed valve ${ }^{2}$ was designed and eight were installed with shroud jet injectors for forced response testing which started June 1995 and ended that October.

A preliminary analysis of forced response data has been accomplished using, in part, an approach suggested by Weigl ${ }^{3}$. The results of this analysis on a planar pulse sine sweep test dataset is presented below. In addition, a rotating stall/surge event is also analyzed and presented for comparison purposes. Data presented were acquired while the engine was operating at ground idle (near $60 \%$ of design speed).

To develop active stall control devices for turbomachinery applications at least one and possibly three important pieces of information must be extracted from the data. First, the approach of rotating stall/surge must be detected with adequate warning time to respond. Second, if two dimensional actuation is desired to inhibit the development of rotating stall/surge, the spatial location in time of those aerodynamic features that promote the development of the dynamic event must be identified. Lastly, the transfer function for the control inputs must be determined. The spatial Fourier analysis is designed, in part, to provide that information. This paper primarily addresses the last of these technical issues.

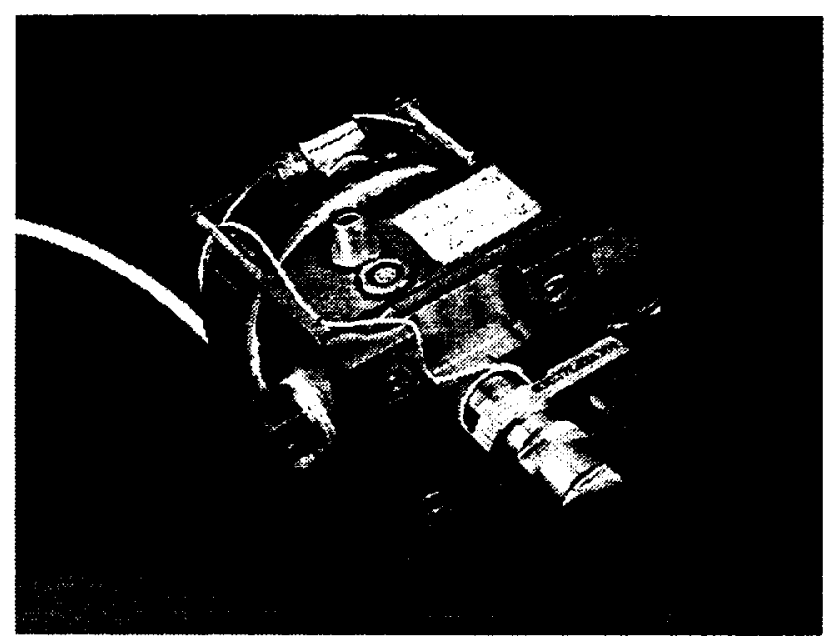

Figure 1. High Frequency Valve and Jet Ejector

\section{TEST AND ANALYSIS FACILITIES}

\section{Introduction}

References by Owen ${ }^{4}$ and a NASA Lewis Research Center Pamphlet ${ }^{5}$ detail the facility, testing, instrumentation, instrumentation locations, data acquisition, and data reduction methodologies and equipment.

For this testing, a waterbrake system and calibrated bellmouth were acquired, on loan, from AlliedSignal. The waterbrake allowed engine operation over the entire power envelope. The bellmouth allowed engine airflow measurements to an accuracy within $50.5 \%$. Eight jet ejectors and a combustor inbleed system were designed and installed to allow a more realistic compressor stage matching during the approach to stalVsurge.

Eight jet ejectors were designed for installation in front of the first stage compressor rotor in existing instrumentation holes with a diameter of $0.95 \mathrm{~cm}$. These pre-existing holes are approximately one chord length upstream of the first stage rotor and are nearly equally circumferentially spaced. Figure 1 is a photograph of one of these ejectors and its controlling valve. Each ejector head is immersed approximately $1 \mathrm{~cm}$ into the inlet and the total frontal area per ejector is about 1.21 sq. $\mathrm{cm} .(-1.5 \%$ of the total inlet area at the compressor front face). For this test, a high response pressure transducer (not visible) was mounted immediately downstream of the ejector opening.

Each ejector was designed to provide $-0.61 \%$ of the design speed engine airflow, (total of $-5 \%$ ), given air supply conditions of $689 \mathrm{kPag}$ and $20^{\circ} \mathrm{C}$, and to provide a jet of air that spans less than $25 \%$ of the passage radially. The ejectors were mounted to provide airflow directly into the engine inlet. 
A voice coil actuated air valve was designed in house and eight were used to control air injection into the engine. As is shown in figure 1 , these valves were mounted immediately over the jet ejector. The machined square block is approximately $7.5 \mathrm{~cm}$ on a side. These valves were designed to control the required airflow and operate proportionally at frequencies up to $450 \mathrm{~Hz}$. Reference [2] provides detailed information concerning the design and development of these valves.

Compressor loading was controlled using a combustor inbleed system specifically designed for this program. Unheated high pressure air was injected immediately downstream of the diffuser exit through 30 openings in the outer combustor casing. The system could deliver over $15 \%$ of the engine design airflow.

\section{Instrumentation, Data Acquisition, and Data Reduction}

High response pressure transducers in front of the first stage rotor were collocated with the jet ejectors. High response pressure transducers in front of the second stage were located at nearly the same circumferential locations as those in front of the first stage. Transducers were numbered in order increasing in the direction of rotation. Circumferential increments were approximately $45^{\circ}$. Fifteen pound absolute $/$ in $^{2}$ pressure transducers were used both at the inlet to stage 1 and the inlet of stage 2. Engine instrumentation included flush mounted hub (wafer) transducers at the exits of the first three stages. These confirmed that rotating stall began in the tip region.

High speed data were recorded digitally using either the LeRC central data acquisition system or, later, an in-facility data acquisition system. High speed channels were digitized at a rate of about 12750 samples/second/channel, providing a bandwidth of approximately 5 $\mathrm{kHz}$. Critical high speed data were also backed up on analog tape (speed of 30 IPS minimum). All high speed data have been analog low pass filtered at approximately $5 \mathrm{kHz}$ to eliminate aliasing. All data were then digitally low pass filtered at $800 \mathrm{~Hz}$ (about 3.5 rotor frequency) and resampled at $2.5 \mathrm{kHz}$ using an inhouse program designed to maintain the signal frequency content. This limit was deemed high enough to allow all pertinent modal information to pass but low enough to eliminate unnecessary noise.

For all tests, steady data were acquired consisting of both research and operational parameters sampled at $1 \mathrm{sample} / \mathrm{second} / \mathrm{channel}$. These data included compressor stage pressures and temperatures and overall engine performance information.

\section{SURGE TEST RESULTS}

\section{Introduction}

This section provides an analysis of a ground idle (near $60 \%$ of design speed) engine dynamic (surge) event. A spatial Fourier analysis (SFA) is included in these comparisons. The SFA accomplished on all data used Syed' ${ }^{6}$ implementation of Garnier's ${ }^{7}$ method. This spatial Fourier analysis technique was first implemented by the Massachusetts Institute of Technology and is based on the work of Moore and Greitzer, a well known approach postulates the existence of very mild momentum disturbances that travel circumferentially about the front face of the compression system. As the compressor approaches the surge line, the system approaches neutral stability and these disturbances grow. At the rotating stall/surge point, the disturbances initiate or develop into rotating stall/surge. Spatial and temporal variations (in this instance, pressure) sensed in the inlet of the compressor are decomposed into their Fourier components circumferentially in space about the compressor inlet. The number of Fourier components (spatial modes) that can be resolved is a function of the number of sensors and, this application, three rotating modes can be resolved (seven required sensors). Detailed explanations of the technique are presented in Paduano $^{8}$, Garnier ${ }^{7}$, and Tryfonidis ${ }^{9}$.

\section{Engine Surge Event}

Figures 2 and 3 show the results of a spatial Fourier analysis of a ground idle surge induced using combustor inbleed and without inlet Mach probes. The figures show partial results of this analysis for test data acquired in front of stage 1 (fig. 2) and in front of stage 2 (fig. 3).

The figures included in this section present analyzed data for approximately the last second prior to the recorded dynamic events. This time interval is a compromise. On one hand, it is short enough to allow a more detailed look at the development of the dynamic events. On the other, the interval is long enough to identify changes that can be used to signal the onset of stall surge. While this paper cannot present a detailed explanation of the spatial Fourier analysis, a short explanation of the figures is included to help orient the reader.

Figures $2 a$ and $3 a$ display the time traces of the eight circumferentially mounted transducers. In these figures, the direction of rotor rotation is up. The $\mathrm{x}$-axis is time measured in units of rotor revolutions and the $y$ axis is non-dimensional pressure, with the pressure traces offset vertically for clarity.

Figures $2 \mathrm{~b}$ and $3 \mathrm{~b}$ plot the location of the modal wave peak (unwrapped phase angle) versus time. As has 
been mentioned, the spatial Fourier analysis decomposes the spatial signal content of the eight circumferential transducers into a summation of sine waves. The first spatial mode represents a single sine wave in one circumference, mode 2 is 2 sine waves in a circumference, and mode 3 is 3 waves. This is done for each time step and the spatial location of the peak of the wave is plotted versus time. If a single frequency becomes dominant in any of the three modes, the rate of change in location becomes constant - the slope of the line becomes straight. Each of the mode phase angles shown in figs. $2 b$ \& $3 b$ has been divided by its

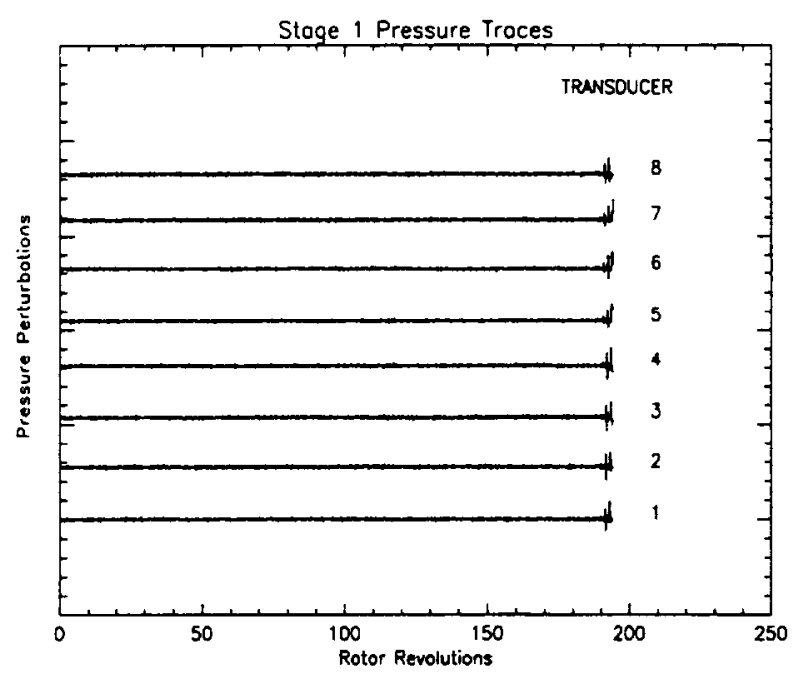

Fig. 2a Static Pressure Traces Stage 1

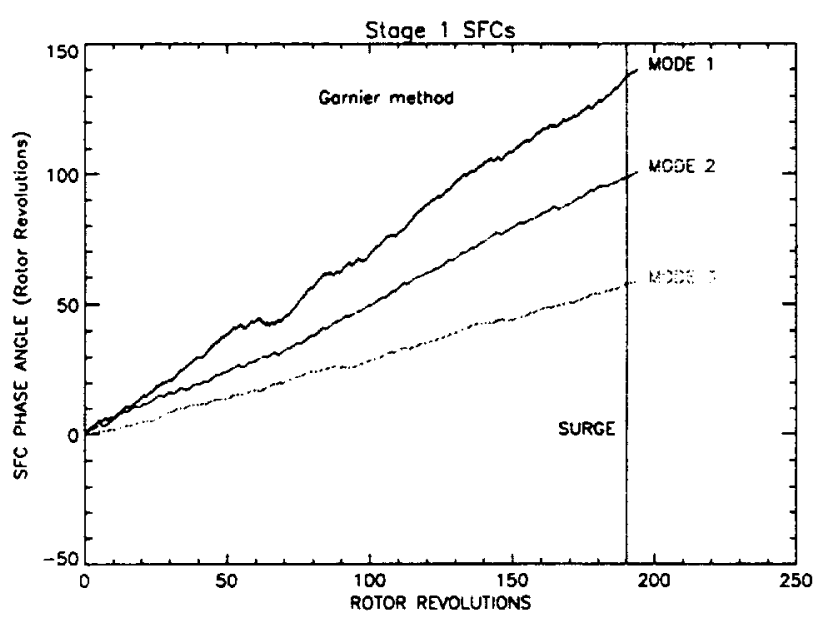

Fig. 2b Phase Angle Traces Stage 1

Figure 2 Stage 1 Spatial Fourier Analysis for Surge Test mode number, which causes the phase angle plots to present the correct rate of change of the modal waves. Phase angle tracking is apparent in front of both stages but no mode clearly shows a constant rate of phase change approaching stall to indicate a single dominant frequency. However, the mode 1 results do show intervals of tracking at $-132 \% \mathrm{RF}$ (rotor frequency), for example, at about $80 \mathrm{RR}$ (rotor revolutions) and again immediately prior to surge. This indicates that the pressure signals, when broken into their spatial Fourier components, contain a mode 1 component that is often dominated by a wave that moves about the front face of

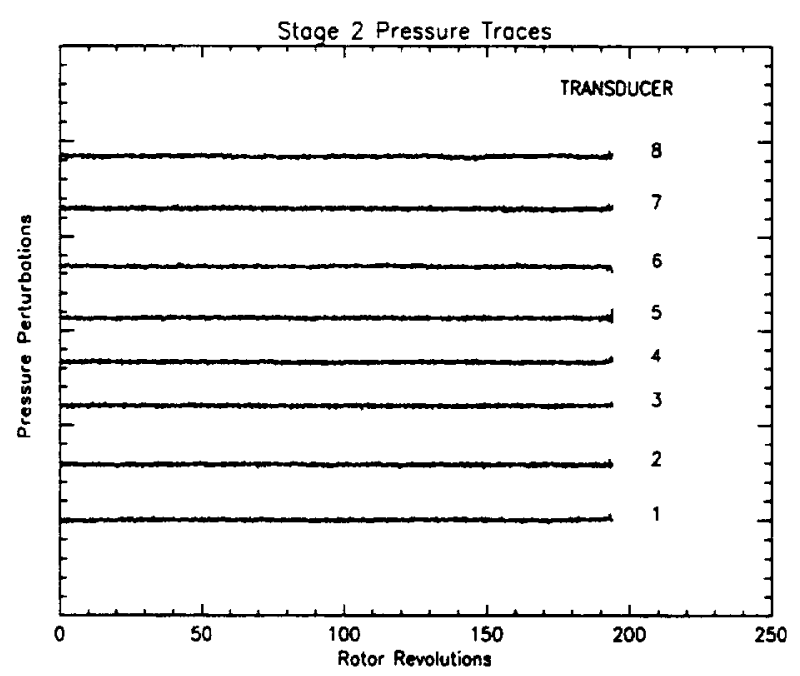

Fig. 3a Static Pressure Traces Stage 2

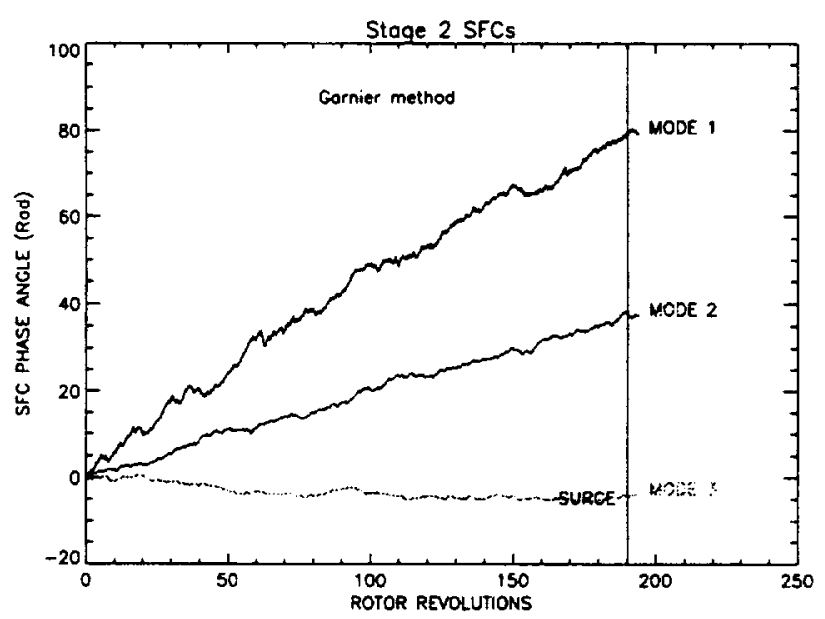

Fig 3b. Phase Angle Traces Stage 2

Figure 3 Stage 2 Spatial Fourier Analysis for Surge Test 


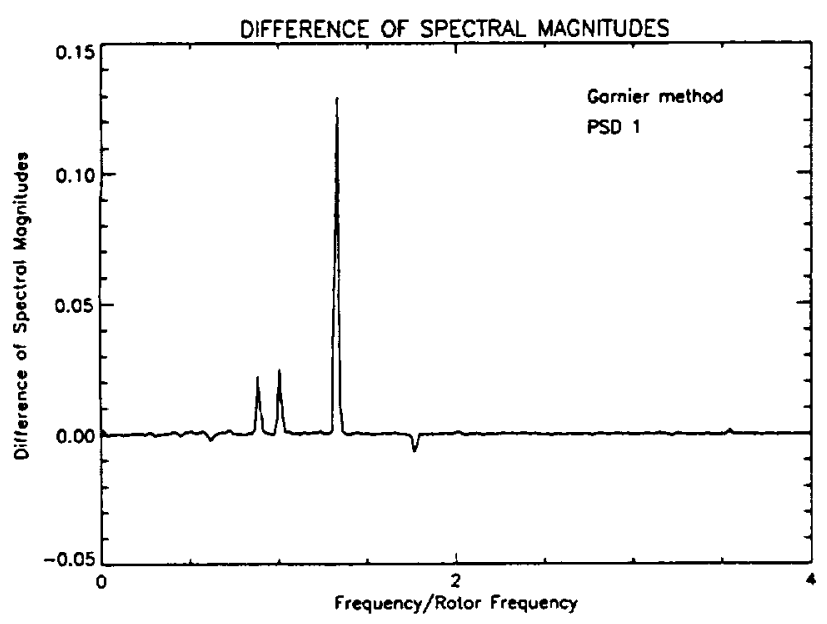

Fig. 2c Mode 1 RMS Magnitude Differences

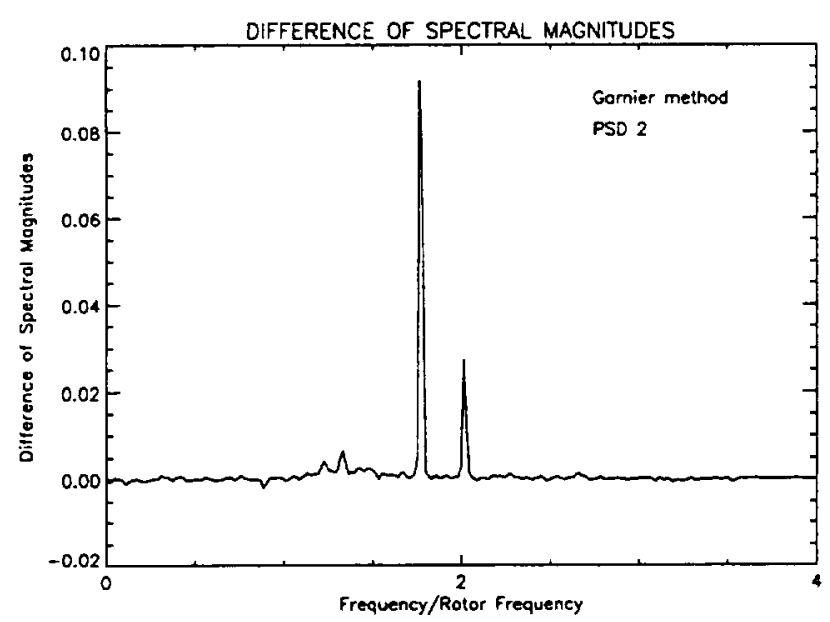

Fig. 2d Mode 2 RMS Magnitude Differences

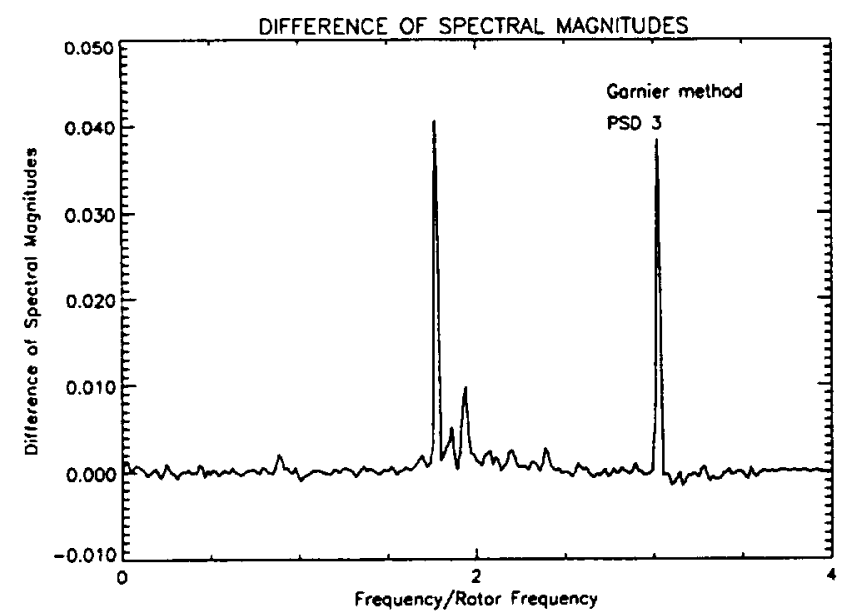

Fig 2e Mode 3 RMS Magnitude Differences Fig. 2 Cont. Stage 1 Spatial Fourier Analysis

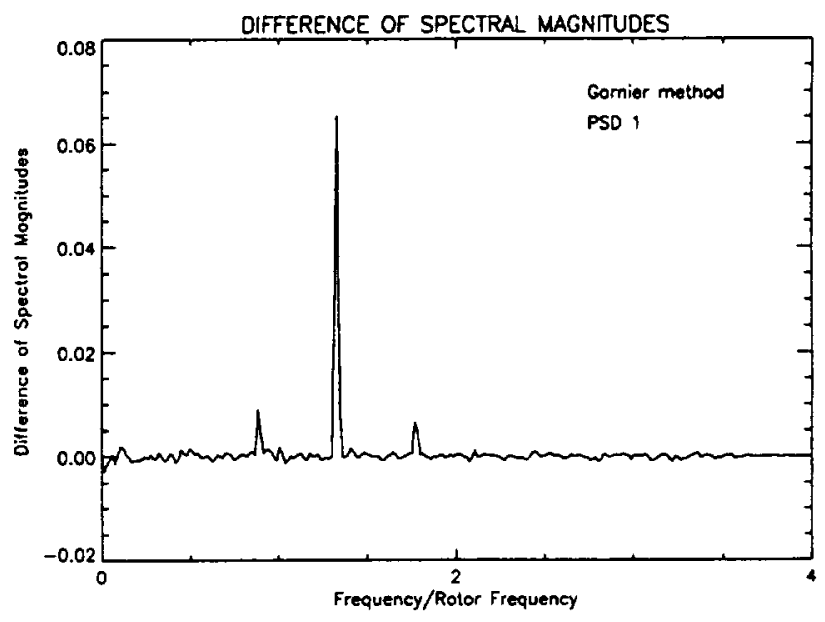

Fig. 3c Mode 1 RMS Magnitude Differences

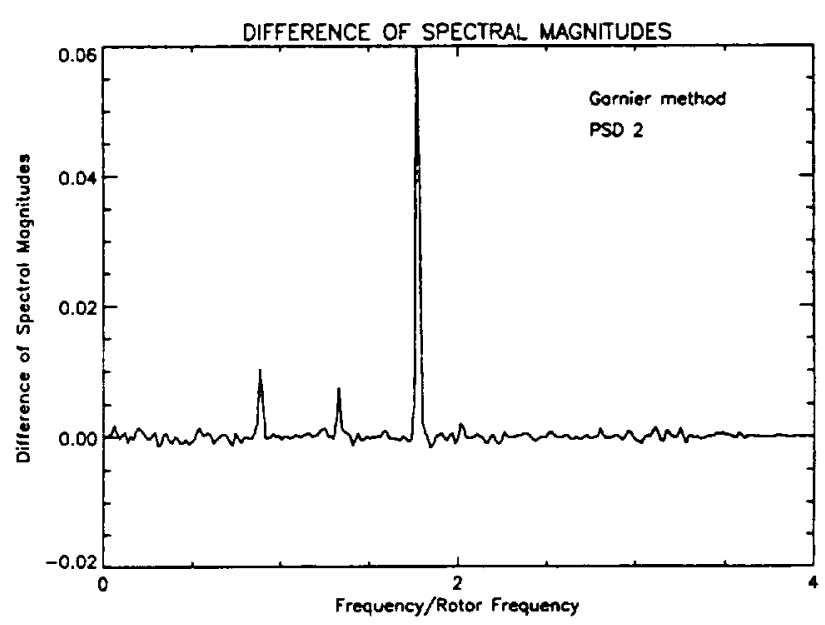

Fig. 3d Mode 2 RMS Magnitude Differences

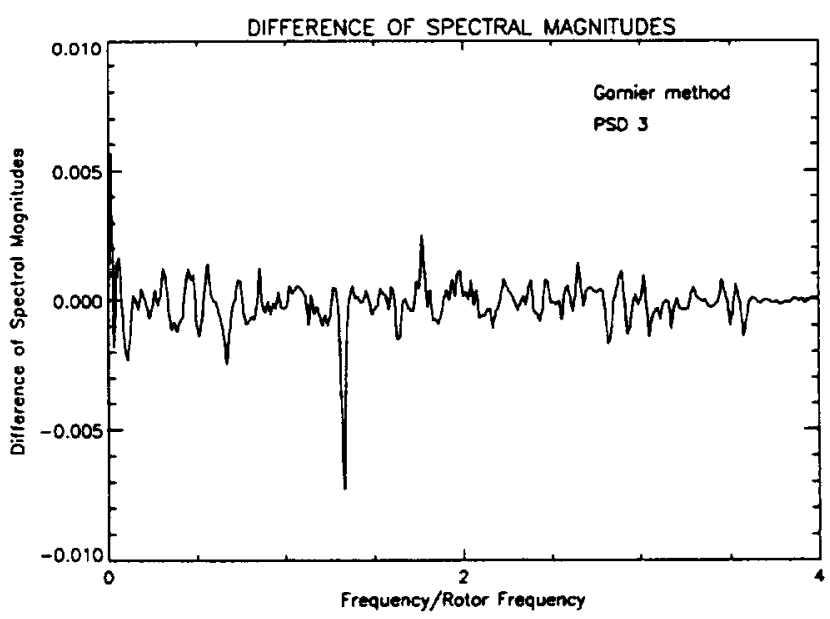

Fig 3e Mode 3 RMS Magnitude Differences Fig. 3. Cont. Stage 2 Spatial Fourier Analysis 
the compressor at $132 \%$ of the rotor speed. However, this tracking is broken up intermittently.

In general, the most constant phase angle tracking in the stage 1 data appears to be in mode 2 . However, a closer inspection of this tracking reveals short sections of steep slopes intermingled with sections of much more disorganized tracking, as is also the case for the third mode.

After the initiation of surge at about $190 \mathrm{RR}$, all modes in front of the first stage (fig. 2b) begin to clearly track a pressure pulse rotating at about $61 \%$ of the rotor speed.

Also notable is the weak phase angle tracking in the stage 2 data (fig. 3b) at any time but particularly after the initiation of surge. Clearly no frequencies are dominant here.

In front of a compressor traveling wave energy of many frequencies exists. Spectral Magnitude (SPM) plots show the relative strengths of the different frequencies that exist in each of the modes Figs. 2c,d,e \& $3 c$,d,e present the SPM differences for the first, second, and third modes. These plots present the overall traveling wave magnitudes (eliminating standing wave components) as a function of frequency for the acquired datasets. The spectral magnitude difference may be defined:

$$
\begin{aligned}
& |S(f)|-|S(-f)| \\
& \quad=\left|F F T\left[S F C_{m}\right](f)\right|-\left|F F T\left[S F C_{m}\right](-f)\right|
\end{aligned}
$$

These are plotted with frequency on the abscissa and a non-dimensional magnitude difference on the ordinate. They represent a summation over time of all the traveling wave energies in the first three modes. Note that the results in figs. $2 c, d, e$ \& $3 c$,d,e have not been divided by the mode number. Therefore, a given frequency in a plot represents a sine wave with the number of cycles per circumference equal to its mode moving at a speed about the circumference that is the displayed frequency divided by the mode number. Remember, the analysis will provide the overall frequency of a sine wave moving about the face of the compressor. For the mode 2 results, there are two sine waves/circumference. Thus, the actual frequency of, for example, the double sine wave of the mode 2 results is only half of the frequency calculated. Finally, references in the text to a specific frequency shown in the spectral difference plots are only approximate.

The results shown in figs. $2 c$,d,e (in front of the stage 1 rotor) show strong traveling energy at a number of discrete frequencies. Mode 1 indicates traveling at $0.9 \mathrm{RF}, 1.0 \mathrm{RF}$, and 1.32 RF. The strongest energy resides at $1.32 \mathrm{RF}$ and this is reflected in the phase

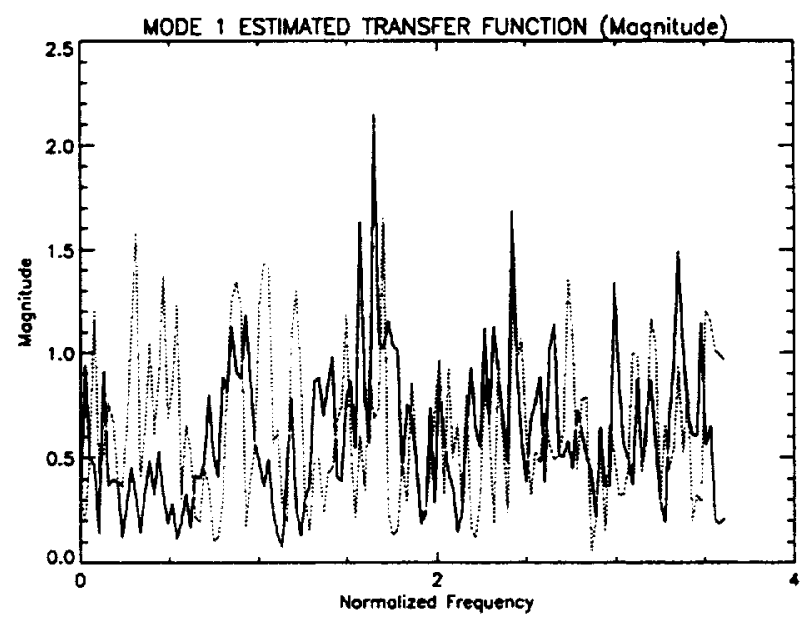

Fig 4a Mode 1 Transfer Function Magnitude

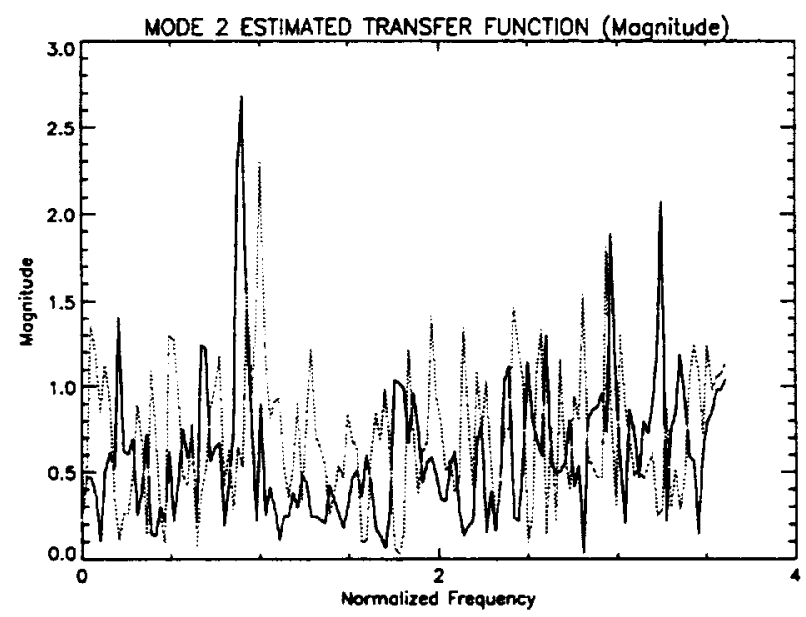

Fig 4b Mode 2 Transfer Function Magnitude

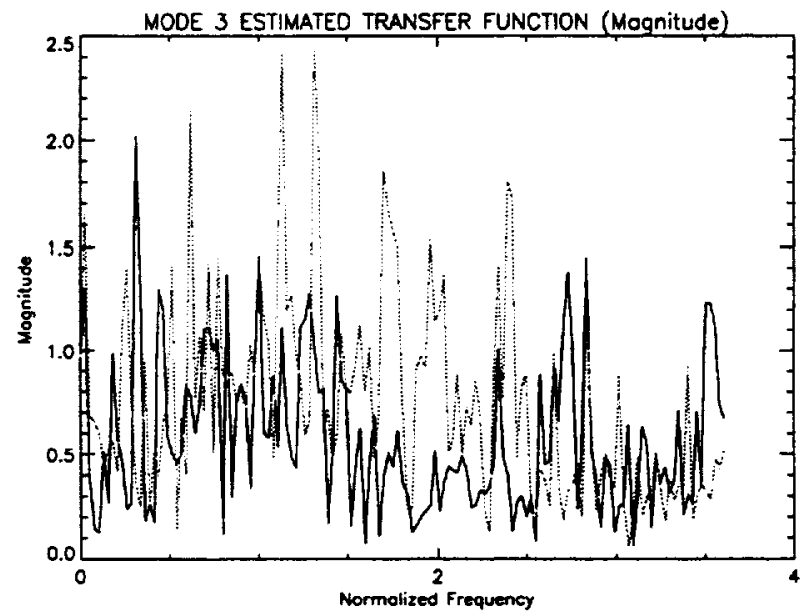

Fig 4c. Mode 3 Transfer Function Magnitude Figure 4 SFA Estimated Transfer Function Magnitudes for Surge Testing 
angle plot (fig. 2b). Mode 2 shows only strong traveling wave energy at 1.8 and $2.0 \mathrm{RF}$, although some exists at 1.32 RF. This $1.8 \mathrm{RF}$ energy would suggest modal phase tracking at $0.9 \mathrm{RF}$ and, although this frequency tracking is apparent at some times in the signal, it does not dominate the phase angle tracking. The strongest traveling wave frequencies in the mode 3 data are at 1.8 and 3.0, implying traveling wave frequencies at around 0.6 and $1.0 \mathrm{RF}$.

Like stage 1 , the stage 2 mode 1 energies indicate traveling energy at 1.32 with less prominent peaks at 0.9 RF (this peak is also somewhat apparent in front of the first stage rotor) and at 1.8 RF. These equidistant peaks at $0.9 \mathrm{RF}, 1.32 \mathrm{RF}$, and 1.8 RF are, because of the equal spacing between them, clearly related. They reflect a single mode 1 wave traveling at about 1.32 RF. However, the amplitude of this wave, as it moves about the front face, varies (somewhat like an AM radio signal). Mode 2 shows the 1.8 RF signal with very weak traveling wave energy at $0.9 \& 1.32 \mathrm{RF}$. Mode 3 energy in front of the second stage is virtually non-existent.

Note for both the stage 1 and stage 2 analysis, mode 1 traveling energy is the strongest with modes 2 somewhat weaker and 3 being very weak.

Although not presented here, strong standing wave are present in the data for all three modes which tend to corrupt the results of the analysis, particularly the phase angle traces presented in figs. $2 b$ \& $3 b$ (and, later, in $6 b$ $\& 7 b$ ).

Finally, certain common frequencies exist in both sets of data. These are 0.9 RF \& 1.32 RF in mode 1 and $1.8 \mathrm{RF}$ in mode 2 . To obtain a better understanding of the relationship between the data acquired at these two locations, a further analysis of this data can be done.

\section{Transfer Function and Coherence}

Weigl $^{3}$ of MIT has suggested a straightforward approach for assessing the relationship between the data acquired at the inlet of stages 1 and data acquired at the inlet of stage 2. This approach involves the calculation of the transfer function across stage 1 and the coherence between the calculated spatial Fourier coefficients. Note that these calculations are not, per se, averaged estimations of the ratios of the temporal Fourier transforms of the input pressure transducer signals but rather averaged estimations of the ratios of the temporal Fourier transforms of the spatial Fourier coefficient (i.e., the 8 point discrete spatial Fourier transform) for any specific mode. The following development of "transfer function" and "coherence" is more completely explained in reference [10], from which this section is condensed.

Note that, in contrast to the spectra in figs. 2 \& 3 which show only traveling wave magnitudes (eliminat-

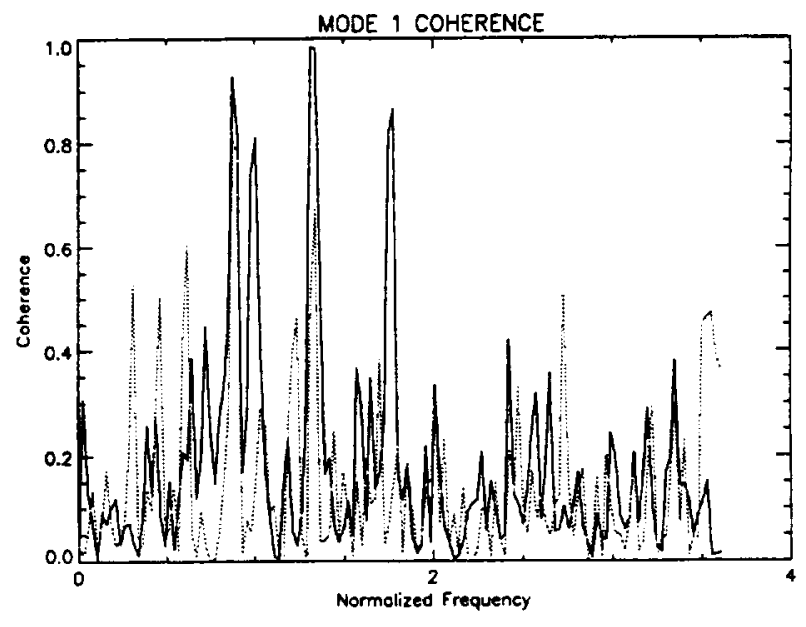

Fig 5a Mode 1 Coherence

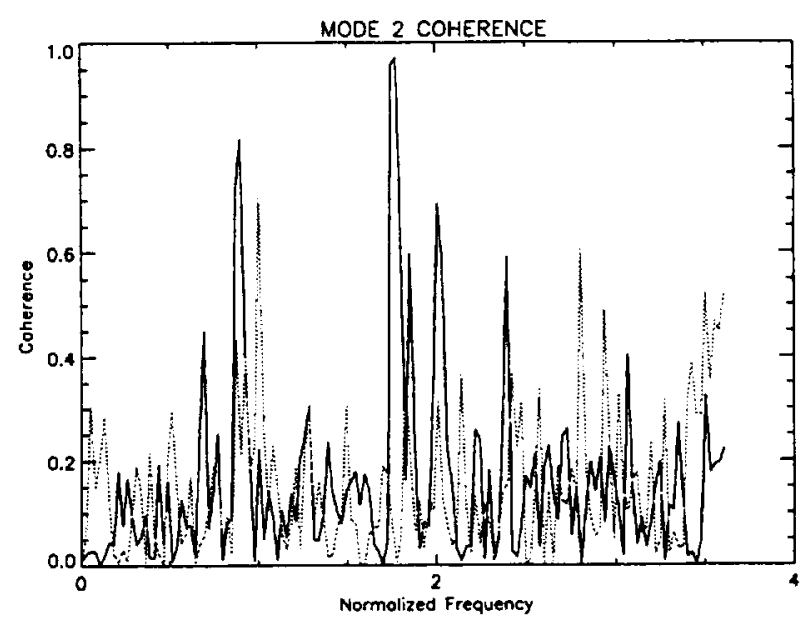

Fig 5b. Mode 2 Coherence

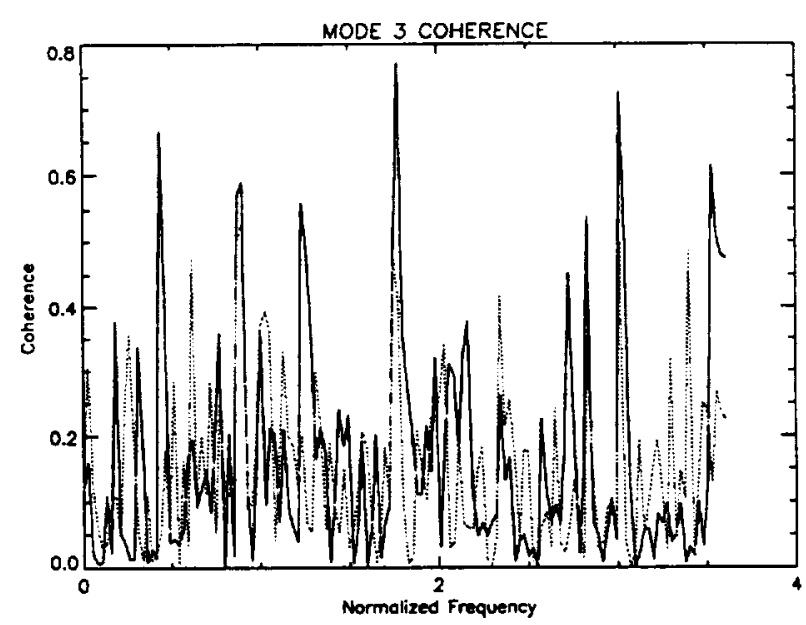

Fig. 5c. Mode 3 Coherence

Figure 5 Spatial Fourier Analysis Coherence for Surge Testing 
ing effects of standing waves), the transfer function magnitude and coherence results shown in figs. 4 \& 5 include the effects of both standing waves and traveling waves.

For this development, the "Cross Power Spectrum" (CPS) is defined as:

$$
G_{x y}(f)=S_{x}^{*}(f) S_{y}(f)
$$

The input autopower spectrum used in the denominator of eqns. $3 \& 4$ may be calculated by multiplying the complex conjugate of desired data by itself in Eq. 2 . The "Transfer Function" is defined as:

$$
\overline{H(f)}=\frac{\overline{G_{x y}(f)}}{\overline{G_{x x}(f)}}
$$

The capital letter " $\mathrm{S}$ " is the discrete Fourier transform, " $f$ " indicates the frequency domain, the overbar denotes averaging, the subscripts $x$ an $y$ are input and output, and the "*" indicates the complex conjugate.

Equation (2) is the product of the complex conjugate of the discrete Fourier transform (DFT) of the input signal and the discrete Fourier transform of the output signal and is the numerator in equation (3). The denominator in equation (3) is the autopower spectrum of the DFT of the input signal. The transfer function definition minimizes the effects of uncorrelated noise in the transducer signals and the transfer function measures the output/input transmission characteristics of a linear system at each frequency.

The "Coherence Function", which varies from zero (no coherence) to one (entirely coherent), is also derived using the CPS. Here, coherence is defined as:

$$
\gamma^{2}=\frac{\overline{G_{x y}(f)} \overline{G_{x y}^{*}(f)}}{\overline{G_{x x}(f)} \overline{G_{y y}(f)}}
$$

This equation provides a measure, at a given frequency, of the proportion of the power in the output signal related to the power of the input signal.

Summarizing, the estimated transfer function magnitude shows the ratio of a systems total output power (including noise) divided by the systems measured input power, as a function of frequency. In the presence of noise, the coherence shows the fraction of output power due the measured input power at the same frequency.

\section{Modal Wave Transfer Analysis}

Rotating stall/surge events in the T55-L-712 engine are clearly complex events involving not only all stages of the compressor but, also, other components of the engine. Nevertheless, it is clear from analyses of surge events at ground idle that surge at this speed is preceded by a rotating stall event that is first observed in the tip region of compressor stage 1 . Thus, the first stage in this system appears to be the critical stage in the development of dynamic events in this compressor. Therefore, the estimated transfer function (Eqn. 3) and coherence (Eqn. 4) relationships were applied to the spatial Fourier coefficients calculated from data acquired in front of the first stage rotor (input) and in front of the second stage rotor (output). The results provided information on the effects of the first compressor stage (the assumed linear system) on the change in the modal waves through the stage and, later, the influence of the jet ejectors on stage dynamic operation. We can now look in detail at the transport of modal waves across the first stage of the compressor.

Figures 4 show the estimated transfer functions for the first three spatial modes across stage 1 . The solid line represents the "forward" traveling wave (in the direction of blade rotation) and the lighter dotted line is the reverse traveling wave. These figures display the relative strengths of signal downstream of the first stage when compared to the upstream location. For example, the forward traveling mode 2 energy at about $0.9 \mathrm{RF}$ is over 2.5 times stronger than the energy upstream of the stage.

To better understand figs. 4, it is helpful to plot the coherence between the two sets of data. This information is presented in figs. 5. Coherence may be looked upon as a measure of the strength of the relationship between the two signals at a given frequency. While it is difficult to establish a "minimum" acceptable coherence, let us specify that a coherence of 0.7 or higher indicates a valid coupling between upstream traveling waves and downstream traveling waves.

If the 0.7 coherence criterion is used, strong mode 1 coherences appear at 0.9 RF (forward and reverse traveling), 1.0 RF (forward traveling), 1.32 RF (forward traveling), and 1.8 RF (forward traveling). There is also a near 0.7 coherence at $1.32 \mathrm{RF}$ for the reverse traveling waves. The transfer functions for $0.9 \mathrm{RF}, 1.32 \mathrm{RF}$, and $1.8 \mathrm{RF}$ are all approximately 1.0 while the transfer functions at $1.0 \mathrm{RF}$ are much lower. However, figs. $2 c \& 3 \mathrm{c}$ indicate strong mode 1 traveling waves are only indicated at around 1.32 RF with a much less prominent peak at 0.9 RF. The results would indicate that the most important mode 1 frequency is at $1.32 \mathrm{RF}$, where the strongest traveling waves exist both upstream and downstream of the stage. At this frequency, the transfer function magnitude is roughly 0.9 , indicating much of the energy is transferred. The modal frequency at $0.9 \mathrm{RF}$ 
is also important, but the size of the modal wave is much smaller.

Mode 2 coherence is strong at $0.9 \mathrm{RF}$ (forward traveling), 1.0 RF (reverse), 1.8 RF, and 2.0 RF (both forward). A review of the spectral magnitude differences shows strong traveling waves only at $1.8 \mathrm{RF}$. The transfer function has a magnitude of over 0.9 at this frequency. The 1.8 RF and 2.0 RF points are clearly harmonics of the lower frequencies that indicate the non-sinusoidal

The mode 3 results clearly indicate that little mode

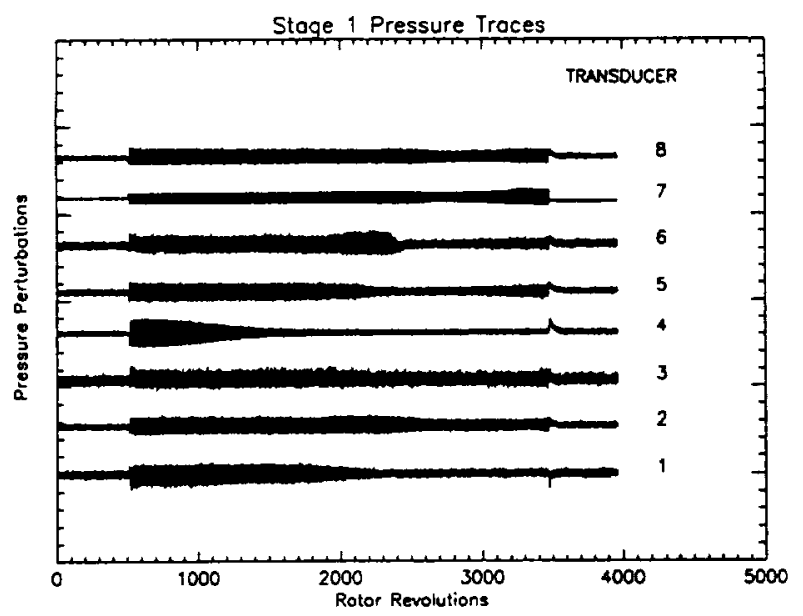

Fig. 6a Stage 1 Pressure Transducers

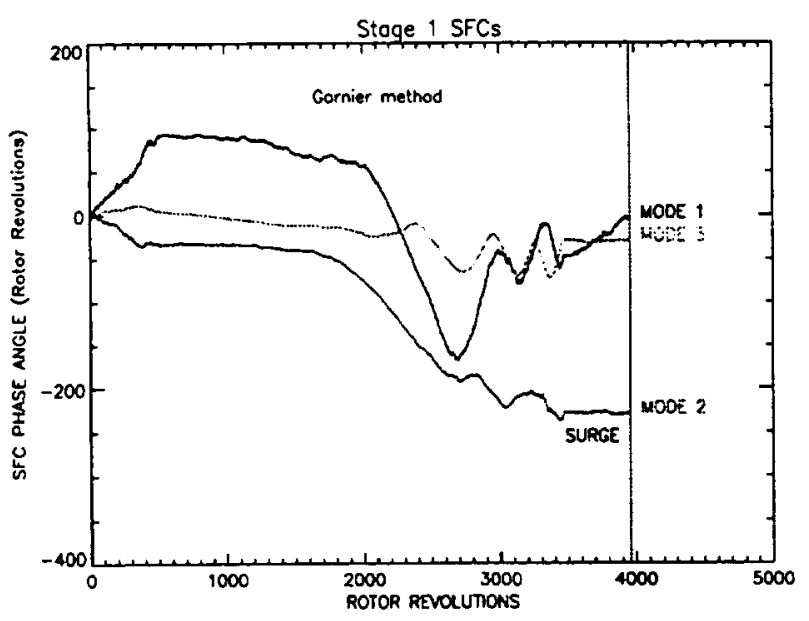

Fig. 6b Stage 1 Phase Angle Tracking Figure 6 Stage 1 Spatial Fourier Analysis for Forced Response Testing
3 traveling wave energy exists behind the first stage. The only acceptable coherences are at $0.4 \mathrm{RF}, 1.8 \mathrm{RF}$, and 3.0 RF but the transfer function at these frequencies indicate very little transfer of modal wave structure across the stage.

\section{Summary of the Engine Surge Event}

It is clear that traveling wave energy of many frequencies exists both in front of the first stage rotor and in front of the second stage rotor and that standing

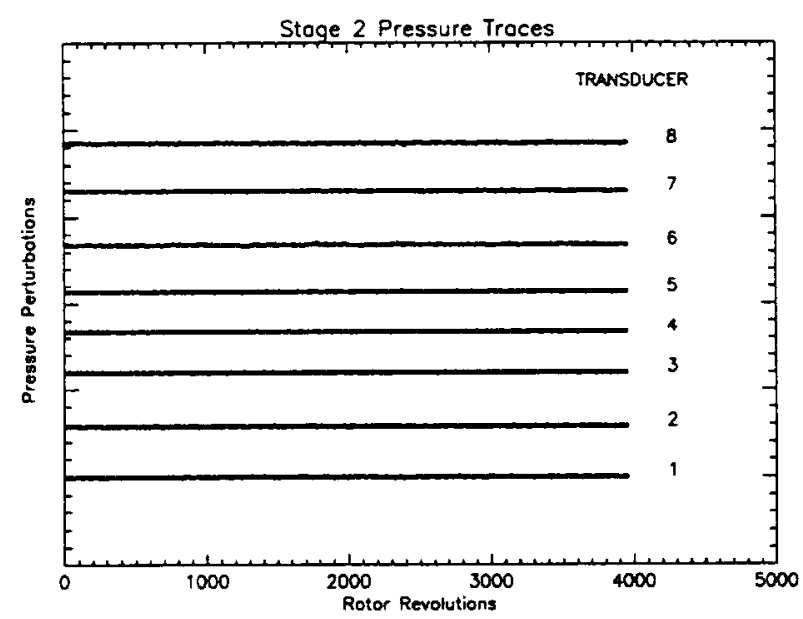

Fig. 7a Stage 2 Pressure Transducers

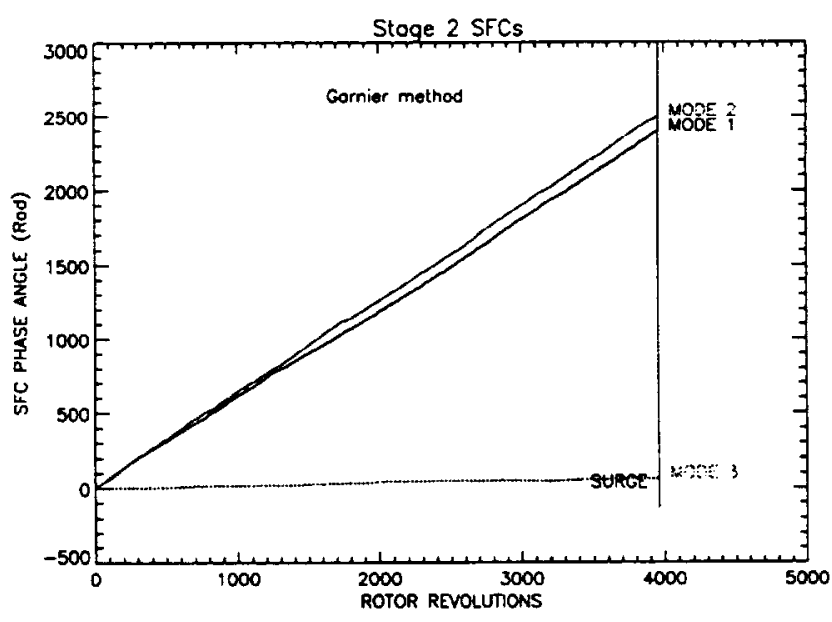

Fig. 7b Stage 2 Phase Angle tracking Figure 7 Stage 2 Spatial Fourier Analysis for Forced Response Testing 


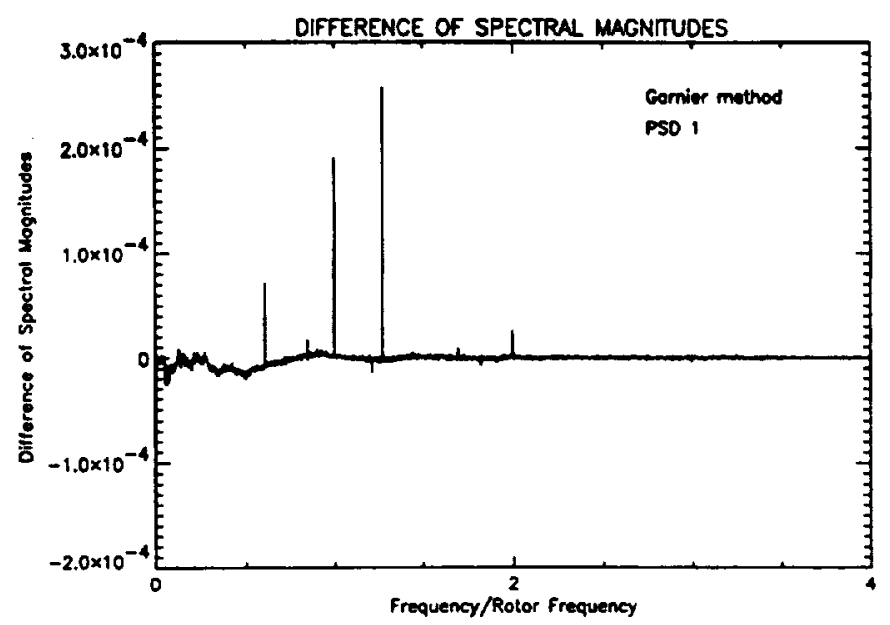

Fig. 6c Mode 1 RMS Magnitude Differences

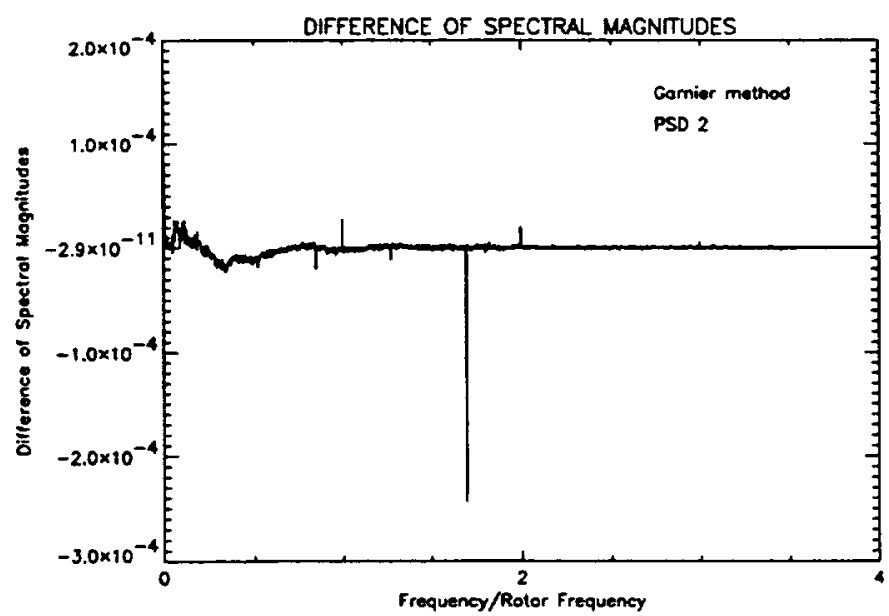

Fig. 6d Mode 2 RMS Magnitude Differences

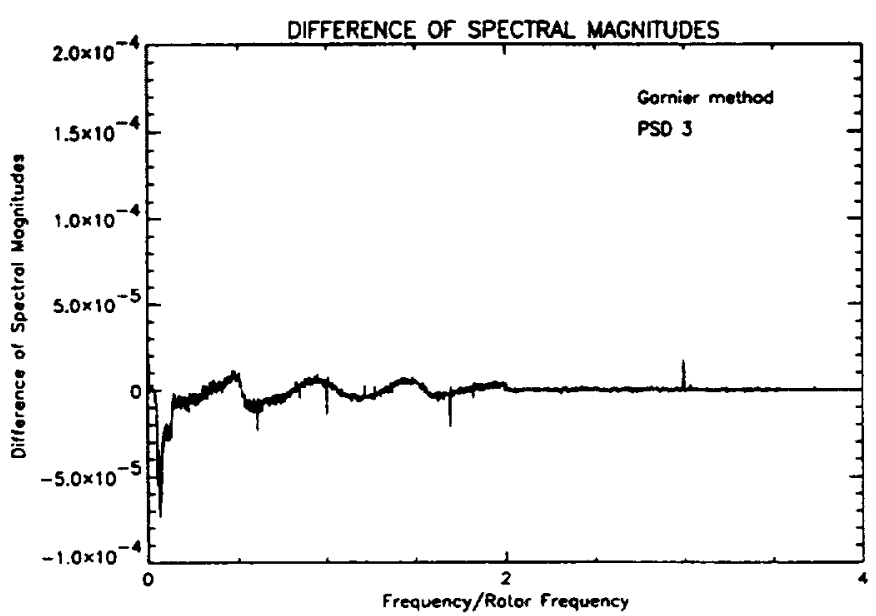

Fig. 6e Mode 3 RMS Magnitude Differences Figure 6 Cont. Stage 1 Spatial Fourier Analysis

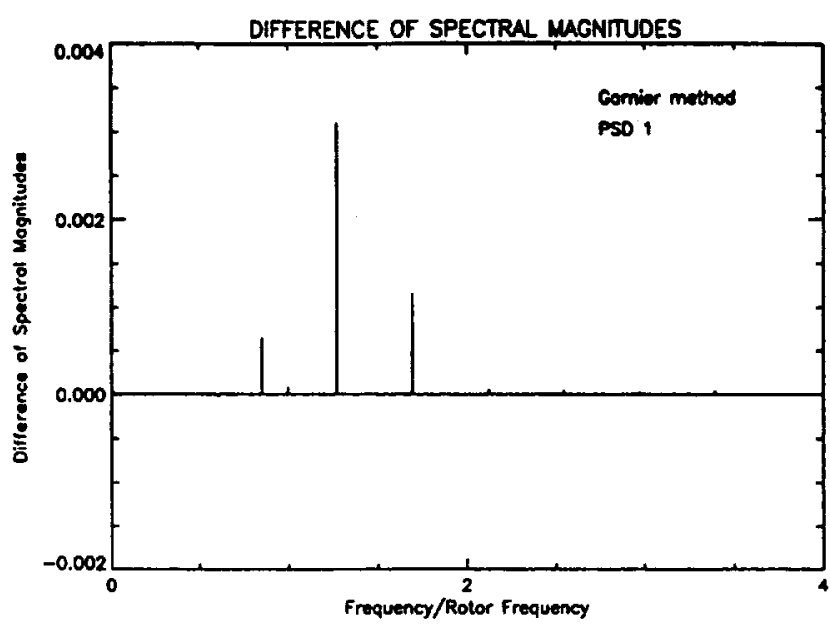

Fig. 7c Mode 1 RMS Magnitude Differences

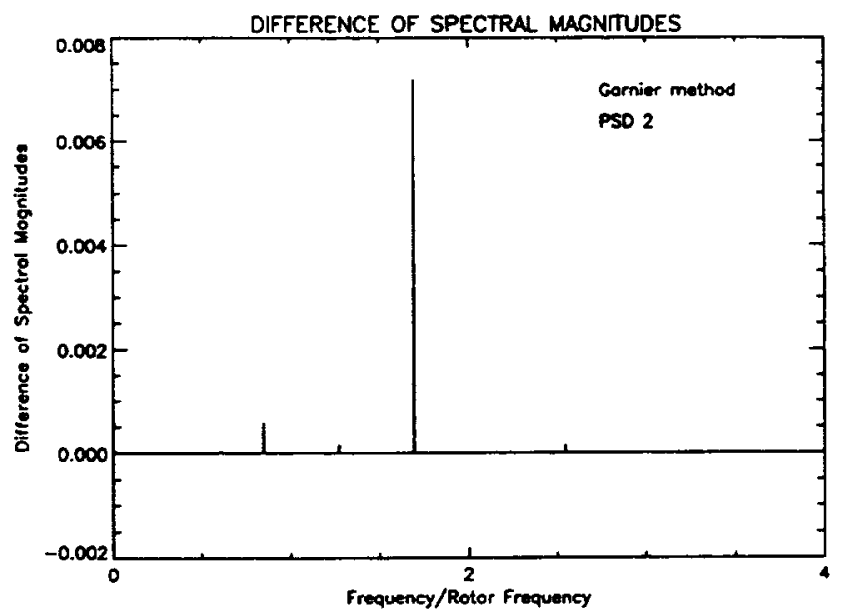

Fig. 7d Mode 2 RMS Magnitude Differences

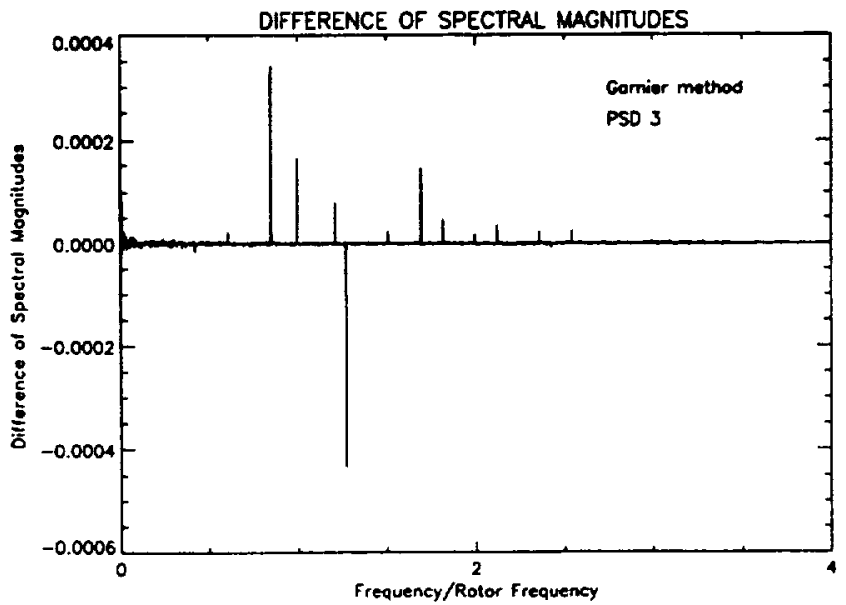

Fig. 7e Mode 3 RMS Magnitude Differences Figure 7 Cont. Stage 2 Spatial Fourier Analysis 
waves of many frequencies exist in the data for all three modes. The traveling wave energies are strongest in the first mode for both stage 1 and stage 2 data with the second mode weaker and the third mode weakest.

A comparison between the stage 1 and stage 2 data indicate that the modal energies are weaker in front of the second stage.

Very few traveling wave frequencies are common to both stages. They can be summarized as follows: for mode 1; $0.9 \mathrm{RF}$ and 1.32 RF (possible 1.8) are common to both stages and for mode 2; $1.32 \mathrm{RF}$ and $1.8 \mathrm{RF}$ are common. No strong modal energies exist in the mode 3 results.

Calculations of the transfer functions and the coherence further restrict those frequencies of importance. Of the prominent frequencies common to both the stage 1 and stage 2 data, only $1.32 \mathrm{RF}$ and, to a much lesser extent $0.9 \mathrm{RF}$ and $1.8 \mathrm{RF}$ are prominent in the Mode 1 results. In the mode 2 results, only at about $1.8 \mathrm{RF}$ are high power signals related. These are the traveling waves that are transported across the first stage. They are the waves most involved in the development of rotating stall at this speed in this stage.

Further, these results will help identify what frequencies are effected during the forced response testing and by the existence of the ejectors.

\section{FORCED RESPONSE TEST RESULTS}

\section{Introduction}

Forced response testing consisted of single valve "sine sweeps", double valve "sine sweeps" and mode "sine sweeps" of the jet ejectors previously discussed. Sine sweeps frequencies began at $10 \mathrm{~Hz}$ and increased smoothly to $450 \mathrm{~Hz}$ in fifteen seconds. A sine sweep is an input sine variation in the valve opening position. The mode of the sweep defines the lag in time between valves. A sweep that has all valves operating in unison is referred to as a "mode 0" sine sweep. However, this is a misnomer since no spatial modal variations occur in this input. A mode 1 sweep, intended to mimic a mode 1 traveling wave, has each adjacent valve lagging its predecessor by $45^{\circ}$. Similarly, a mode 2 sweep has each adjacent valve lagging its predecessor by $90^{\circ}$. The purpose of this type of experiment is to excite frequencies in the compressor and to quantify compressor response to valve inputs.

Discussed below is a planar pulse sweep of all eight valves. It is presented as a representative example of the testing done and highlights problems as well as results associated with these tests. For this particular sweep, combustor inbleed was approximately $0.8 \mathrm{lbm} / \mathrm{sec}$ of air, thereby reducing the compressor airflow by that

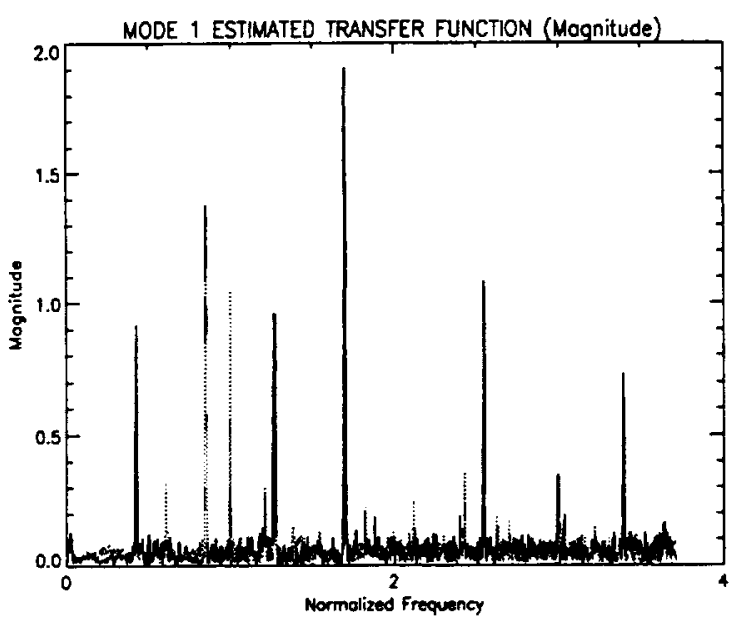

Fig. 8a Mode 1 Transfer Function

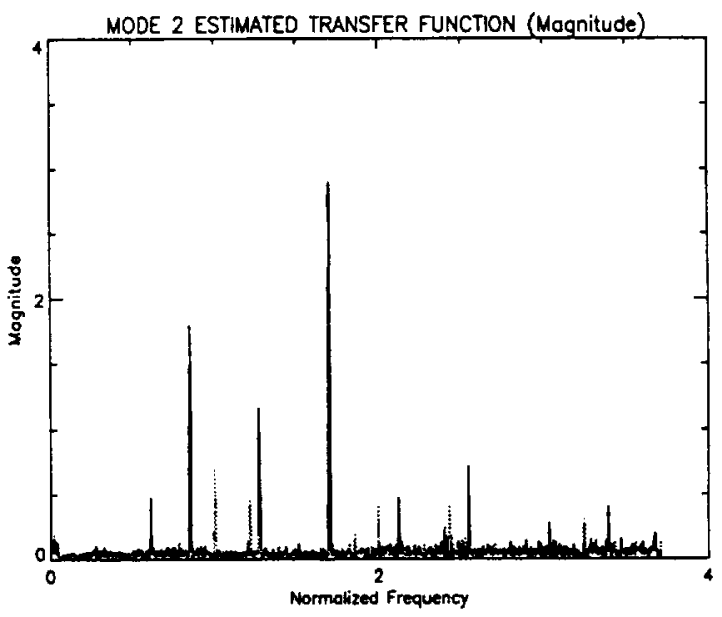

Fig. $8 \mathrm{~b}$ Mode 2 Transfer Function

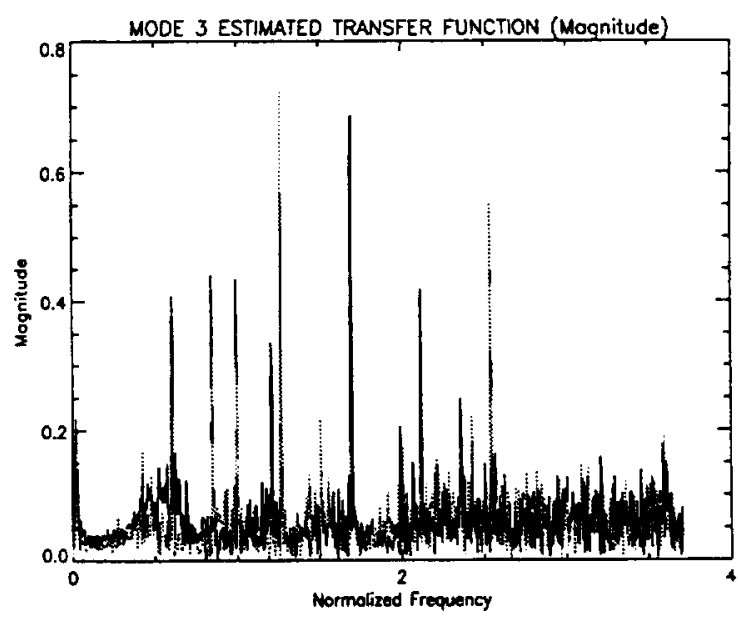

Fig. 8c Mode 3 Transfer Function

Figure 8 SFA Estimated Transfer Functions for Forced Response Testing 


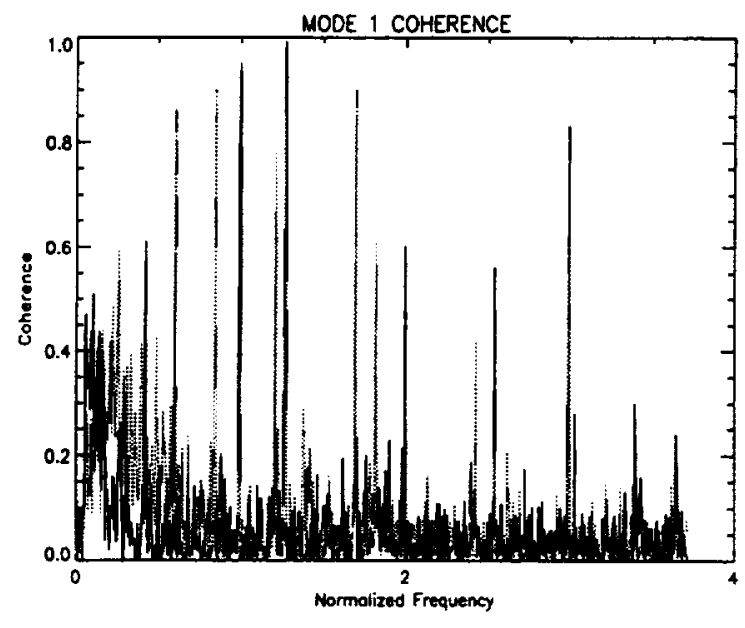

Fig. 9a Mode 1 Coherence

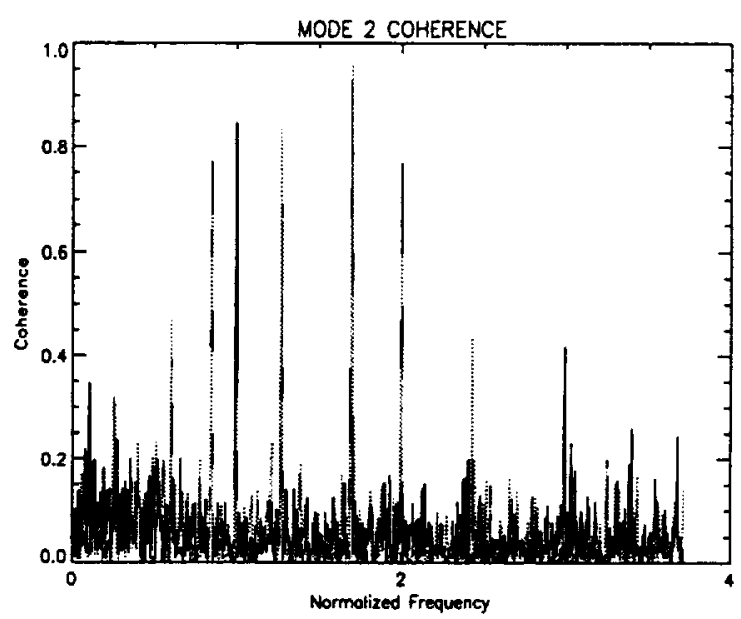

Fig. $9 \mathrm{~b}$ Mode 2 Coherence

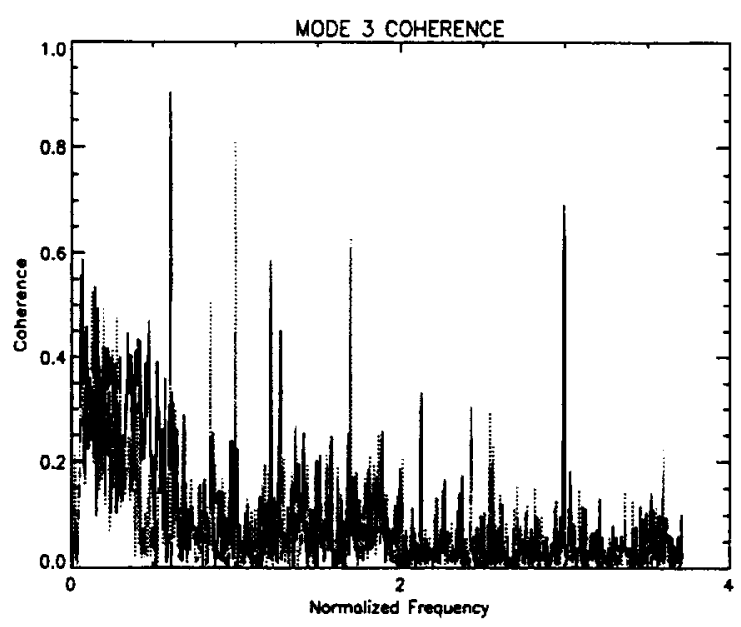

Fig. 9c Mode 3 Coherence Figure 9 SFA Coherence amount and allowing compressor operation closer to the nominal surge line. The test procedure called for the ejector valves to be set at $25 \%$ of full open at the start of the sweep. Thus, the ejectors contributed to the compressor airflow and did modify the compressor operating conditions.

Figure 6a is the time trace of the transducers collocated with the jet ejectors in front of the first stage and fig. 7a shows the transducers in front of the second stage rotor. The transducers in front of the second stage rotor were located at essentially the same circumferential locations as those in front of the first stage. Therefore, each of these transducers was nearly downstream of a stage 1 transducer and it's collocated jet ejector.

Notice in fig. 6a that all of the jet ejectors did not operate equally well. Specifically, ejectors 1,4 , and 6 appeared to less effective at higher frequencies (over $100 \mathrm{~Hz}$ ) and ejectors 2, 5, and 7 clearly did not have a uniform response over all frequencies. The controllers for these ejectors were of an analog rather than digital design, making consistent operation of the valves extremely difficult.

Also notice that there is no clearly obvious effect on the stage 2 transducers shown in fig. 7a.

\section{Spatial Fourier Analysis}

Initially, we will consider the higher modes that are excited as a result of the existence and operation of the valves during this planar pulse sweep. This will identify system differences and non-linear effects.

Figures $6 \mathrm{~b} \& 7 \mathrm{~b}$ show remarkable results. In contrast with the results of the surge event shown in figs. $2 b$ and $3 \mathrm{~b}$, the first stage (fig. $6 \mathrm{~b}$ ) shows no phase angle tracking while the transducers in front of the second stage (fig. $7 \mathrm{~b}$ ) clearly show strong phase angle tracking for both modes 1 and 2 . The tracking frequencies in front of the second stage rotor appear to be about $61 \%$ of the rotor speed.

During the forced response test, as previously mentioned, the jet ejectors were initially set to $25 \%$ of nominal full open and actuated at $\pm 12.5 \%$ of their nominal rated massflow. It would appear that the presence of the jet ejector flows in front of the first stage rotor disrupt the development of simply overwhelm any modal waves at the compressor inlet. Attempts to surge at ground idle with the ejectors operating during these tests have indicated that the compressor operates stably at much lower massflow although this improvement has yet to be quantified.

Power spectral differences are shown in figs. $6 c, d, e$ and $7 c, d, e$. The long data acquisition time for this test (approximately 20 seconds) explains the extreme resolution of frequencies displayed in these figures. 
Mode 1, stage 1 forced response test SPM difference (fig. $6 c$ ) shows strong energies at $0.6 \mathrm{RF}, 1.3 \mathrm{RF}$, and 1.7 RF. The 0.6 RF signal is generated in the 2500$3500 \mathrm{RR}$ time period, as shown in fig $6 \mathrm{~b}$. Mode 2, stage 1 results for the forced response test (fig. 6d) has a characteristic spike at -1.7 RF. This negative traveling wave energy is the reason for the overall negative tracking shown in fig. $6 \mathrm{~b}$ for mode 2 . Mode 2 data also contains a smaller traveling wave at about $0.85 \mathrm{RF}$.

Mode 1, stage 2 data (fig. 7c) show sharp spikes at 0.85 RF, 1.3 RF, and 1.7 RF. As was mentioned in the surge data analysis, $1.7 \mathrm{RF}$ is twice the 0.85 frequency and the strong $1.3 \mathrm{RF}$ signal bisects the two. Mode 2, stage 2 results (fig. 7d) have a very strong forward traveling wave at $1.7 \mathrm{RF}$ with much weaker peaks at 0.85 RF and 1.3 RF. Curiously, there exists no traveling wave energy at the apparent phase angle slope shown in fig $7 \mathrm{~b}$ for either modes 1 or 2 .

Mode 3 data for both stages (figs $6 \mathrm{e}$ and $7 \mathrm{e}$ ), while much clearer than the surge event data, again reflect extremely weak signals.

\section{Modal Wave Transfer Analysis}

A review of the coherence and transfer function calculations (figs 9) would indicate a large number of high coherence frequencies with strong transfer functions (for example, mode 1 frequencies include $0.6,0.85,1.0$, $1.2,1.3,1.7$, and 3.0 RF). To isolate the important frequencies, the results of the PSD analysis must be used.

For the mode 1 traveling waves, $0.6 \mathrm{RF}, 1.3 \mathrm{RF}$, and 1.7 RF show high coherences. The 1.3 RF shows a transfer through the stage of nearly 1.0 and the $1.7 \mathrm{RF}$ is enhanced through the stage with a transfer function of almost 2.0. Similarly, both the mode 2 traveling wave energies of $0.85 \mathrm{RF}$ and $1.7 \mathrm{RF}$ show a strong transfer function of 2.0 and 3.0 with high coherences for both.

Mode 3 shows three strong coherences, at $0.6 \mathrm{RF}$, 1.0 RF, and 3.0 RF, but the transfer functions and PSD magnitudes at those frequencies are extremely weak.

\section{Comparison Between the Surge Experiment and the Forced Response Experiment (Modes 12, and 3)}

A detailed comparison between the forced response test data and the surge data reveal much commonality between the two datasets (as would be expected), but there do also exist differences.

Mode 1, stage 1 surge data includes a peak at 0.9 RF while the forced response data includes a $0.6 \mathrm{RF}$ peak. Both contain 1.0 RF and 1.3 RF traveling wave energy.

Mode 2, stage 1 data both contain strong traveling

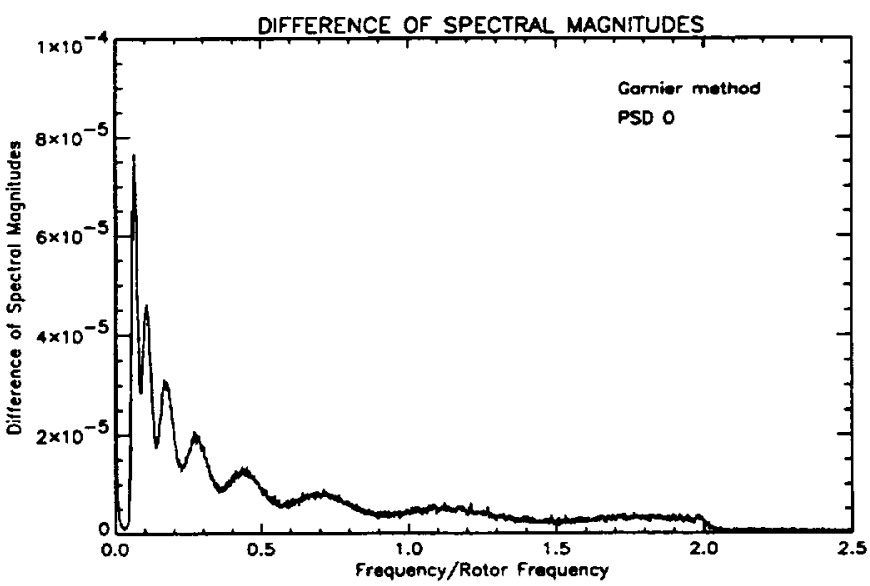

Fig. 10a Valve Spectral Magnitude

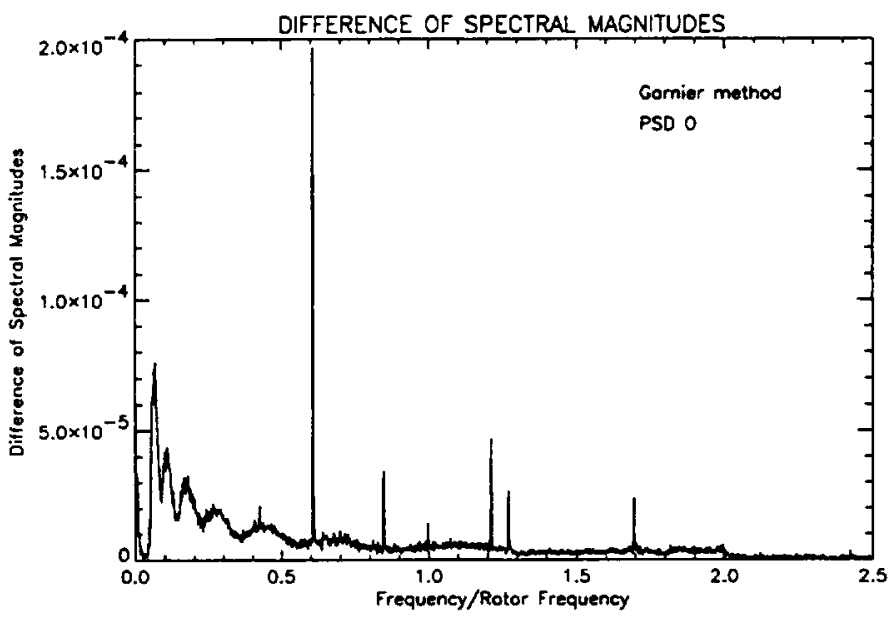

Fig. 10b Stage 1 Spectral Magnitude

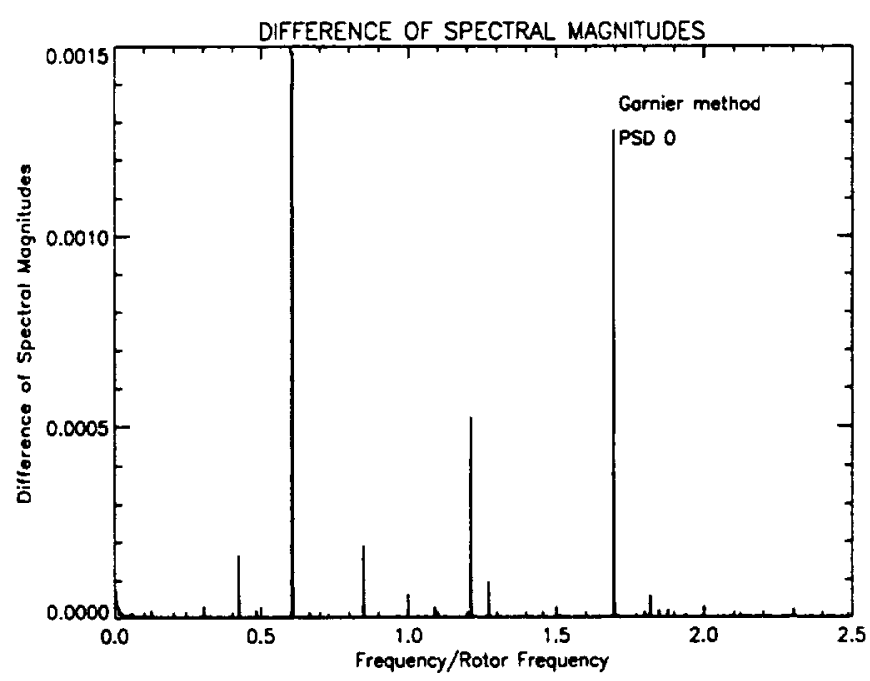

Fig 10c. Stage 2 Spectral Magnitude Figure 10 Spectral Magnitude, Planar Pulse, for Forced Response Testing 


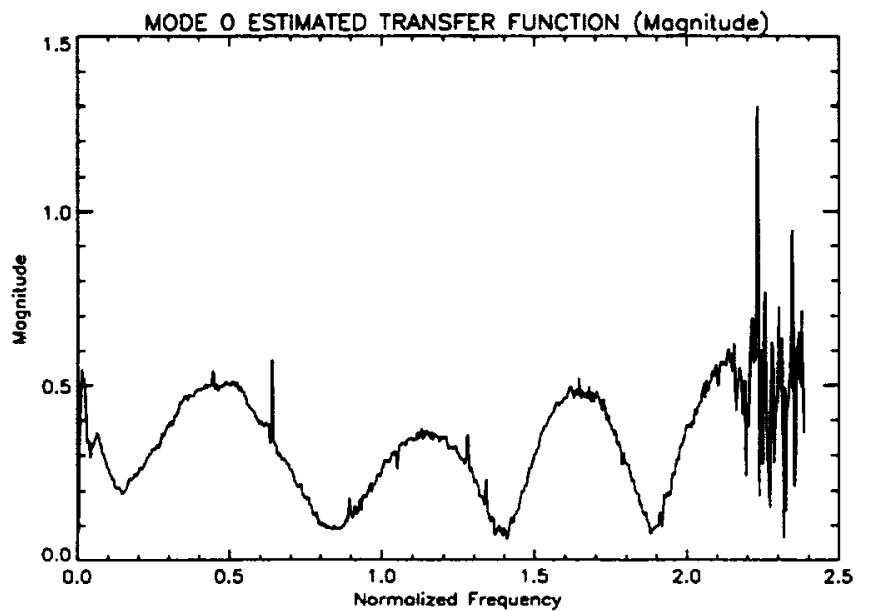

Fig.1la Command - Stage 1 Transducer Transfer Function

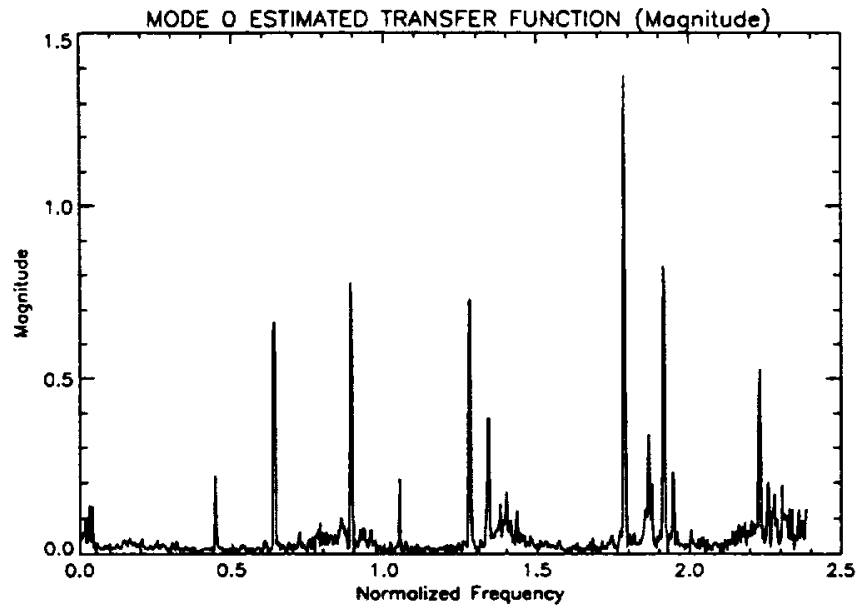

Fig. 11b Stage 1 - Stage 2 Transducers Transfer Function

Figure 11 Planar Pulse Transfer Functions

wave signals at 1.7-1.8 RF but the forced response results are apparently traveling in the reverse direction. The signal at 2.0 RF exists for both but is much damped in the forced response results.

Mode 3 surge data, while weaker than the more fundamental modes, still contains traveling waves at $1.8 \mathrm{RF}$ and 3.0 RF while these are not at all apparent in the forced response results.

In front of the second stage, mode 1 results are similar for both sets of data with traveling energies at 0.85 RF, $1.3 \mathrm{RF}$, and 1.75 RF.

Similarly, mode 2 results are very similar between the two sets of stage 2 data with common frequencies at approximately $0.85,1.3 \mathrm{RF}$, and $1.7 \mathrm{RF}$ with the last

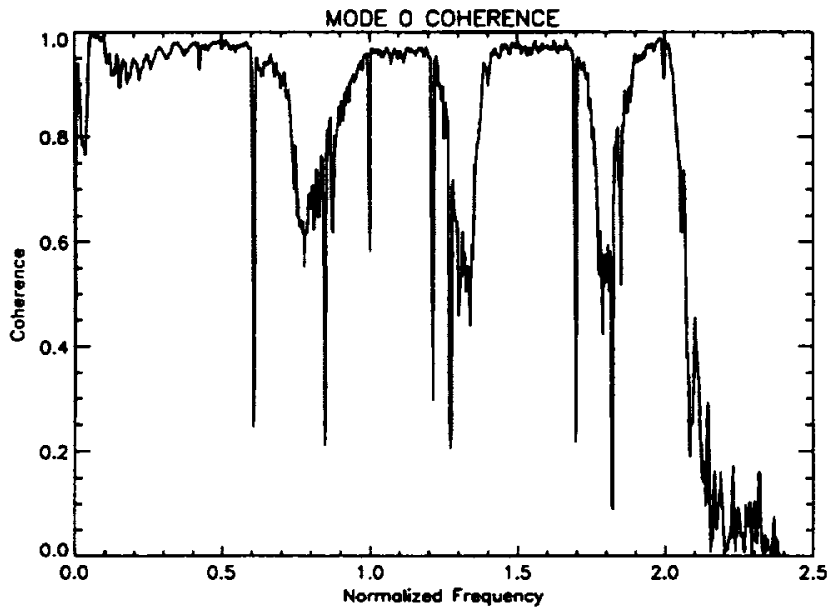

Fig. 12a Command - Stage 1 Transducer Coherence

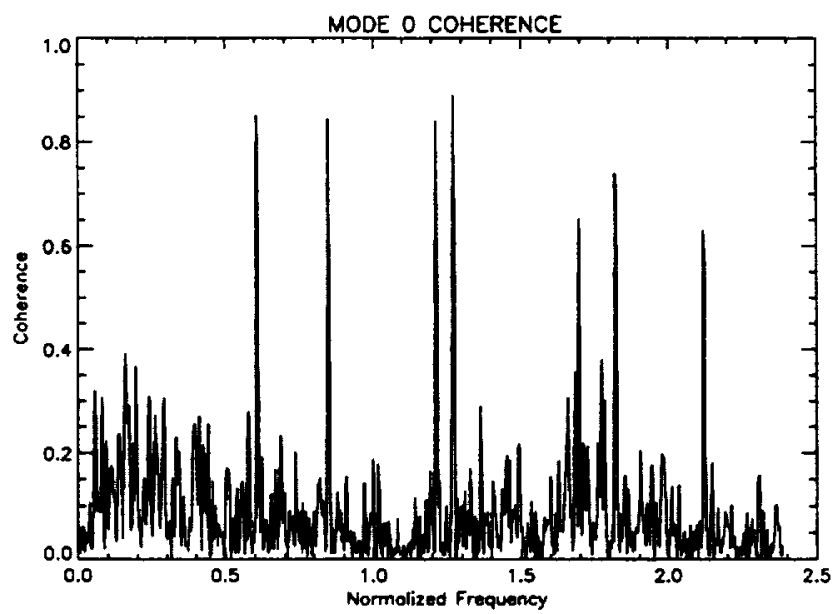

Fig. 12b Stage 1 - Stage 2 Transducer Coherence

Figure 12 Planar Pulse Coherence

being the strongest by far.

The existence of the ejectors during the forced response experiment excited a mode 1 traveling wave at $0.6 \mathrm{RF}$ when actuated at higher frequencies (above 200 $\mathrm{Hz}$ ) in front of the first stage rotor. It strengthened the 1.0 RF signal for mode 1. It also induced a strong mode 2 reverse traveling wave at 1.7 RF. Lastly, it damped the mode 3 traveling wave energies.

The traveling wave content in front of the second stage appeared largely unaffected by the ejectors.

The transfer functions, however, indicated that at modal frequencies with strong coherence, the presence of the ejectors greatly increased the strength of the energy enhancement across the stage 1 for $1.3 \mathrm{RF}$ in 
mode 1 and $1.7 \mathrm{RF}$ in mode 2.

\section{Planar Pulse (Mode 0) Spatial Fourier Analysis}

Figure 10 presents the planar wave energy for the valve commands, stage 1 pressure transducers, and stage 2 pressure transducers during the planar pulse sweep. Since these are planar pulse calculations, the plots do not present differences, but, rather, the positive frequency output of a temporal FFT calculation on the valve command or transducer pressure averaged over eight transducer (or valve) locations at each sample time.

Since the valve command plot does not show input pressure traces but valve position commands, fig. 10a merely shows the desired signal inputs. The valve command signal clearly shows a planar wave content.

The processed spectral magnitudes from the data acquired by the stage 1 transducers show considerable planar data wave energy. Peaks exist at about $0.6 \mathrm{RF}$ and, also, at about 1.2 RF.

Figures 11a \& 11b show the estimated transfer function magnitudes between the average commanded valve position and the first stage transducers (fig 11a) and between the stage 1 and stage 2 transducers (fig. $11 b)$. Figures $12 \mathrm{a} \& 12 \mathrm{~b}$ show the coherence calculations that correspond to figs. $11 \mathrm{a} \& 11 \mathrm{~b}$.

It is clear from figure 11a that there is a strong transfer in the system between the commanded valve positions and the transducer location upstream of the compressor. These occur over large regions of the input frequency sweep. The coherences shown in fig. 12a also indicate this with very high coherences across most of the frequencies of interest. The drops in coherence at $\sim 0.8 \mathrm{RF}, \sim 1.3 \mathrm{RF}$, and $\sim 1.8 \mathrm{RF}$ are currently under study. These drops do imply that, at these frequencies, the planar pulses occurring are not driven by the valves but by other system dynamics.

The transfer of the planar pulse across the first stage is much less clear. Certainly, there exists a slightly higher coherence between $0.0 \mathrm{RF}$ and $0.5 \mathrm{RF}$ but this coherence is still very much lower than the desired 0.7 . With the exception of a very low frequency (approximately in the range of the surge frequency) transfer function in the range of $0.05 \mathrm{RF}$, the transfer function is very low with the exception of sharp spikes at a number of frequencies. Acceptably high coherences exist only at 0.6 RF, 0.85 RF, 1.2 RF, 1.3 RF, and 1.7 RF.

\section{Summary of the Forced Response Experi- ment}

The existence of jet ejectors in front of the com- pressor clearly affected the operation of the first stage of the compression system. Traveling wave energy in front of the first stage rotor was damped over most of the planar pulse sweep, including that portion of the experiment where the ejectors were fixed at a single valve position. However, at higher valve frequencies, a mode 1 traveling wave emerged that appeared to travel at $\sim 60 \%$ of the rotor speed.

The existence of jet ejectors apparently enhanced the phase angle tracking in front of the second stage rotor but no strong spectral magnitude peak exists at the apparent frequency of travel.

At the inlet of stage 1, strong PSD signals exist at 0.6 RF, 1.3 RF, and 1.7 RF for mode 1. Strong PSD signals exist for $-1.7 \mathrm{RF}$ for mode 2 . At the inlet for stage 2 , strong PSD signals exist for $0.85 \mathrm{RF}, 1.3 \mathrm{RF}$, and 1.7 RF. These peaks reflect a traveling wave of varying magnitude that is moving at approximately 1.3 RF. No strong energy exists in the third mode.

The transfer function/coherence analysis indicate that mode 1 transfer of coherent signals occur at 1.3 RF (transfer of $\sim 1.0$ ) and 1.7 RF (transfer of $\sim 2.0$ ) while the mode 2 transfer of signal occurs at $0.85 \mathrm{RF}$ (transfer of 2.0) and 1.7 RF (transfer of -3.0 ).

Clearly there exists a strong planar pulse transfer function with high coherence between the valve position command and the compressor inlet static pressure over most of the frequencies excited by the valves. However, the transfer across the first stage is very much weaker. Nonetheless, certain very low frequencies (in the probable range of surge cycles) show an indication of higher energy transfer and higher coherence.

Once again, certain frequencies appear in the planar pulse transfer function. These are 0.9 RF, 1.3 RF, and $1.7 \mathrm{RF}$.

\section{CONCLUSIONS}

1) It is clear that several wave frequencies dominate the data presented here. They are at about $0.9 \mathrm{RF}, 1.3$ RF, and 1.75 RF. They are transferred across stage 1 with little damping or with amplification. One or more of these frequencies exists in the planar pulse, modes 1 , and mode 2 sets of data. They frequencies appear to be coupled to each other, across the stage and in the various modes.

2) The ejectors clearly affect the traveling wave (Modes 1 and 2) development in front of the first stage by damping the development. Above $250 \mathrm{~Hz}$ (roughly the last $30 \%$ of the valve sweep), the ejectors enhance the development of a traveling wave at about $60 \% \mathrm{RF}$ in front of stage 1. It would appear that they can be an effective controlling mechanism for active stall control at ground idle. 
3) The presence of the ejectors enhances the transfer of energies across stage 1 at about 1.3 RF (mode 1) and at about 1.7 RF (mode 2).

4) The ejectors enhance the phase angle tracking in front of the second stage rotor, probably by the disruption of weak traveling waves in front of stage 2 .

5) There exist a strong system coherence between the valve command and stage 1 (compressor inlet) transducers over the valve actuation range with the exception of three frequencies bands centered around $0.75 \mathrm{RF}, 1.3$ $\mathrm{RF}$, and $1.8 \mathrm{RF}$.

6) The transfer function and coherence results across the first stage are ambivalent but some indications exist that low frequency planar pulses are transferred across the first stage.

\section{APPLICATION TO ACTIVE STALL CONTROL}

The presented data indicate that the traveling wave energies at $\sim 0.9 \mathrm{RF},-1.32 \mathrm{RF}$, and $\sim 1.7 \mathrm{RF}$ are the important wave energies at this engine speed. It is also likely that they are strongly coupled.

It is apparent that the jet injectors used in this experiment can be effective in this engine at ground idle as the disruption of traveling waves in front of the first stage clearly indicate.

The analysis technique presented here will aid in quantifying the effects of the ejectors at given frequencies. It shows the traveling wave frequencies of importance in the compressor first stage at ground idle. This planar pulse sweep shows that certain frequencies respond to the planar pulse inputs, specifically, 1.32 RF (mode 1) and 1.7 RF (mode 2).

These data have also clearly highlighted the dominant frequencies in this compressor at ground idle. However, these results have not shown the effectiveness of the ejectors at exciting a particular traveling wave frequency. This information will be obtained from the analysis of the Mode $1 \& 2$ sine sweep data.

\section{ACKNOWLEDGMENTS}

The authors wish to publicly recognize several persons and organizations crucial to this program. Mr. Omar Syed, Mr. Tom Griffin, Mr. Barry Piendl, and the entire ECRL staff are thanked for the long days during trying times. Dr. Arun Sehra of AlliedSignal provided continuing support and advocacy of the program. Mr. George Bobula, Dr. Walt Merrill, and Dr. Sanjay Garg provided important program support and advocacy.

A special recognition is extended to Mr. Harald Weigl for his assistance in developing this technique.

This program is a part of JDAPS dynamic engine modeling work.

\section{REFERENCES}

1. Sehra, A.K., "The Promise of Active control for Helicopter and Tank Engines", Workshop on Intelligent Turbine Engines for Army Applications, Cambridge, Ma, March 21-22,1994.

2. Mattern, D.L., and Owen A.K. "A Voice Coil Actuated Air Valve for Use in Compressor Forced Response Testing", presented at the 1995 SPIE Aerosense Conference, Orlando, Fl, SPIE Vol 2494, paper \#2494-19.

3. Weigl, H., Personal Communication, Jan, 1996.

4. Owen, A.K., "Analysis of Rig Test Data for an Axial/Centrifugal Compressor in the $12 \mathrm{Kg} / \mathrm{Sec}$ Class", Presented at the AGARD $82^{\text {nd }}$ PEP, Montreal, Can., Oct 4-8, 1993.

5. "The Engine Components Research Laboratory", Aeropropulsion Facilities and Experiments Division, Lewis Research Center, Aug 1993.

6. Syed, O.A. Personal communication, March 1994.

7. Garnier, V.H., "Experimental Investigation of Rotating Waves as a Rotating Stall Inception Indication in Compressors", Gas Turbine Laboratory Report GTL \#198, Massachusetts Institute of Technology, Nov 1989.

8. Paduano, J.D., “Active Control of Rotating Stall in Axial Compressors", PhD Dissertation, Massachusetts Institute of Technology, GTL Report \#208, March, 1992.

9. Tryfonidis, M., Etchevers, O., Paduano, J.D., Epstein, A.H. and Hendricks G.J.,'Pre-Stall Behavior of Several High-Speed Compressors", Presented at the ASME IGTI, the Hague, Netherlands, Jun 1994.

10. "The Fundamentals of Signal Analysis", Appendix A, Application Note 243, Hewitt Packard Corp., Feb 1985. 



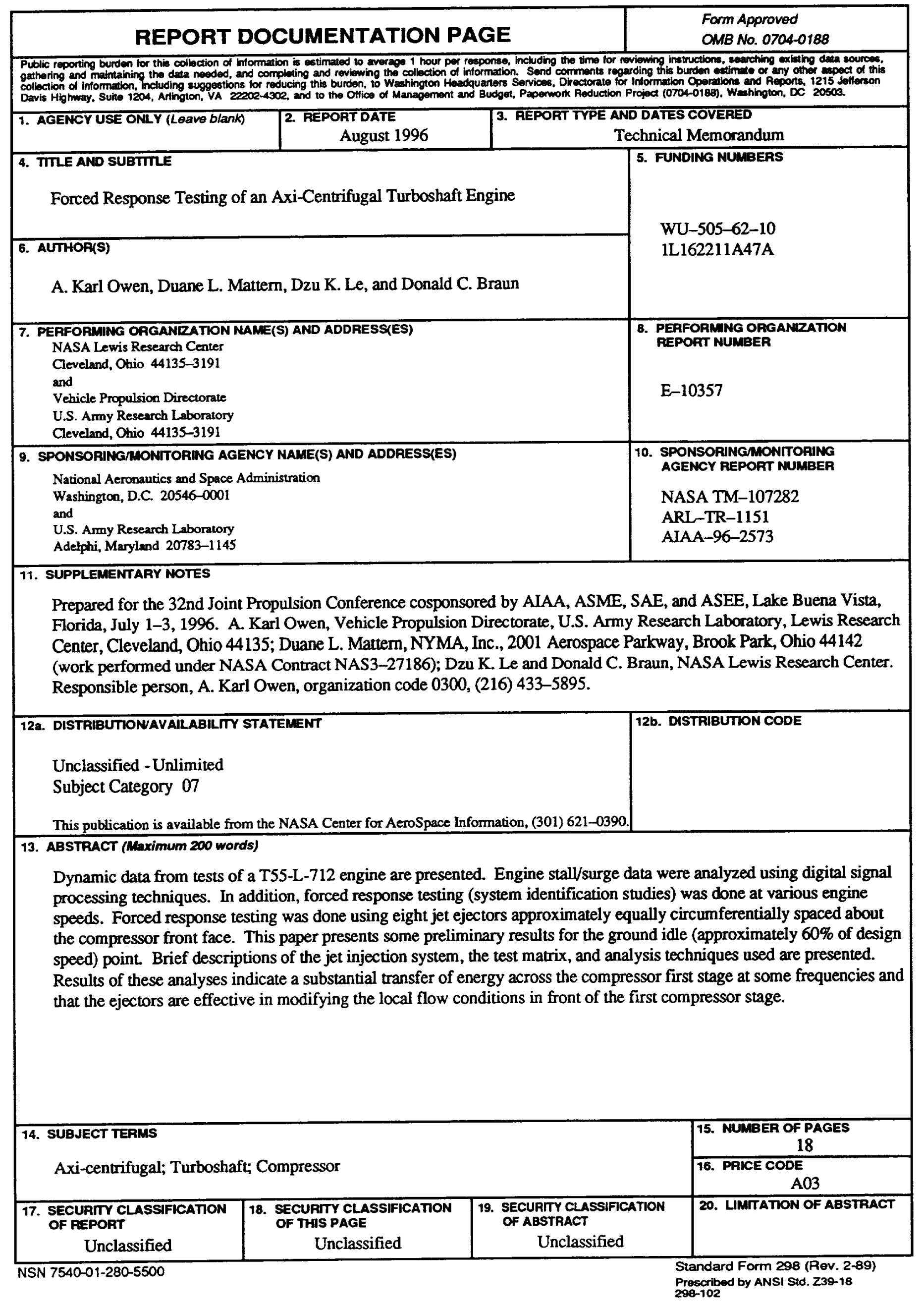





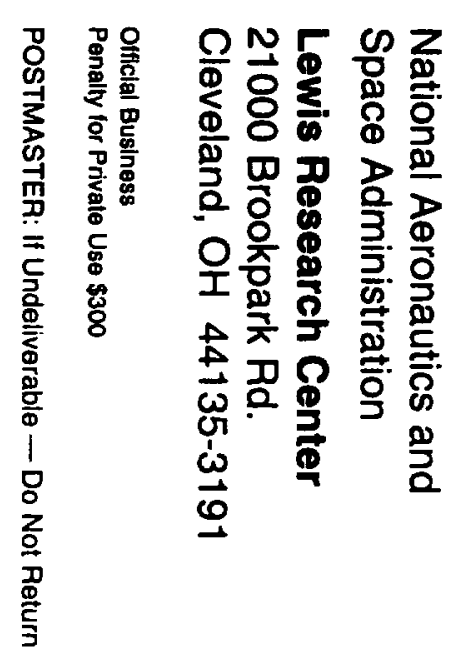

